\title{
Archaeosomes varying in lipid composition differ in receptor-mediated endocytosis and differentially adjuvant immune responses to entrapped antigen
}

\author{
G. DENNIS SPROTT, ${ }^{1,2}$ SUBASH SAD,${ }^{1}$ L. PERRY FLEMING, ${ }^{1}$ CHANTAL J. DICAIRE, ${ }^{1}$ \\ GIRISHCHANDRA B. PATEL ${ }^{1}$ and LAKSHMI KRISHNAN ${ }^{1}$ \\ ${ }^{1}$ Institute for Biological Sciences, National Research Council, 100 Sussex Drive, Ottawa, Ontario, Canada K1A OR6 \\ ${ }^{2}$ Author to whom correspondence should be addressed (dennis.sprott@nrc.ca)
}

Received September 11, 2002; accepted December 10, 2002; published online January 31, 2003

\begin{abstract}
Summary Archaeosomes prepared from total polar lipids extracted from six archaeal species with divergent lipid compositions had the capacity to deliver antigen for presentation via both MHC class I and class II pathways. Lipid extracts from Halobacterium halobium and from Halococcus morrhuae strains 14039 and 16008 contained archaetidylglycerol methylphosphate and sulfated glycolipids rich in mannose residues, and lacked archaetidylserine, whereas the opposite was found in Methanobrevibacter smithii, Methanosarcina mazei and Methanococcus jannaschii. Annexin V labeling revealed a surface orientation of phosphoserine head groups in M. smithii, M. mazei and M. jannaschii archaeosomes. Uptake of rhodamine-labeled M. smithii or M. jannaschii archaeosomes by murine peritoneal macrophages was inhibited by unlabeled liposomes containing phosphatidylserine, by the sulfhydryl inhibitor N-ethylmaleimide, and by ATP depletion using azide plus fluoride, but not by $H$. halobium archaeosomes. In contrast, $\mathrm{N}$-ethylmaleimide failed to inhibit uptake of the four other rhodamine-labeled archaeosome types, and azide plus fluoride did not inhibit uptake of H. halobium or H. morrhuae archaeosomes. These results suggest endocytosis of archaeosomes rich in surface-exposed phosphoserine head groups via a phosphatidylserine receptor, and energy-independent surface adsorption of certain other archaeosome composition classes. Lipid composition affected not only the endocytic mechanism, but also served to differentially modulate the activation of dendritic cells. The induction of IL-12 secretion from dendritic cells exposed to H. morrhuae 14039 archaeosomes was striking compared with cells exposed to archaeosomes from 16008. Thus, archaeosome types uniquely modulate antigen delivery and dendritic cell activation.
\end{abstract}

Keywords: antibody, archaea, cytotoxic T lymphocyte, liposomes, phagocytosis, phosphatidylserine.

Abbreviations: $\mathrm{A}_{\mathrm{M}}=$ macrocyclic archaeol; $\mathrm{A}_{\mathrm{S}}=$ archaeol (the 2,3di-O-sn-2,3-diphytanylglycerol lipid core, after the recommendations of Nishihara et al. (1987)); $\mathrm{A}_{\mathrm{S}}-\mathrm{P}=$ archaetidic acid; $\mathrm{A}_{\mathrm{S}}-\mathrm{PE}=$ archaetidylethanolamine; $\mathrm{A}_{\mathrm{S}}-\mathrm{PS}=$ archaetidylserine; $\mathrm{C}_{\mathrm{S}}=$ caldarchaeol (2,2',3,3'-tetra-O-dibiphytanyldiglycerol (Nishihara et al. 1987));
$\mathrm{C}_{\mathrm{S}}-\mathrm{P}=$ caldarchaetidic acid; $\mathrm{CTL}=$ cytotoxic $\mathrm{T}$ lymphocyte DMPG = dimyristoylphosphatidylglycerol; FBS = fetal bovine serum; GM-CSF = granulocyte macrophage colony stimulating factor; $\mathrm{IL}=$ interleukin; $\mathrm{LPS}=$ lipopolysaccharide; $\mathrm{MHC}=$ major histocompatibility complex; MTT = dimethylthiazol diphenyltetrazolium bromide; $\mathrm{m} / z=\mathrm{M}^{-}$, mass to charge ratio for the molecular anion; OVA = ovalbumin; $\mathrm{P}=$ phosphate; $\mathrm{PBS}=$ phosphate buffered saline; $\mathrm{PI}=$ L- $\alpha$-phosphatidylinositol; PS $=\alpha$-phosphatidylserine.

\section{Introduction}

Archaeosome vesicles, composed of the polar lipids unique to the Domain Archaea (Kates 1988, 1992), have strong mixed adjuvant activities. Immunization of mice with archaeosomeencapsulated proteins results in humoral (Sprott et al. 1997b, Krishnan et al. 2000a) and cell-mediated immune responses, measured as antigen-dependent proliferation of splenic cells, and substantial production by these cells of gamma interferon (Th1 cytokine) and interleukin-4 (Th2 cytokine) (Krishnan et al. $2000 a$ ). In addition to MHC class II presentation, Methanobrevibacter smithii archaeosomes induced strong MHC class I presentation of associated protein antigens by antigen presenting cells, both in vitro and in vivo (Krishnan et al. 2000b). The induced cytotoxic $\mathrm{T}$ cell response was $\mathrm{CD}^{+} \mathrm{T}$ cell dependent, as removal of effector $\mathrm{CD}^{+} \mathrm{T}$ cells abrogated killing of target cells, and primarily perforin mediated, as killing was not induced in perforin deficient mice. Further, processing of antigen was Brefeldin A sensitive, suggesting that antigen presentation by $M$. smithii archaeosomes occurred via the classical cytosolic pathway with peptides being transported through the endoplasmic reticulum and presented by MHC class I molecules (Krishnan et al. 2000b). Comparisons with conventional phosphatidylcholine/phosphatidylglycerol/cholesterol liposomes showed that only protein encapsulated within M. smithii archaeosomes could be presented via the MHC class I pathway (Krishnan et al. 2000b).

Protein antigen entrapment in archaeosomes composed of the total polar lipids from either Thermoplasma acidophilum or Halobacterium salinarum also results in MHC class I and 
class II presentations in vivo (Krishnan et al. 2000b, Conlan et al. 2001). This implicates antigen delivery in vivo to both cytosolic and phagosome compartments of the antigen presenting cells. We now demonstrate that archaeosomes composed of the total polar lipids from various extreme halophiles and methanogens with differing lipid structural properties interact differently with various antigen presenting cells, but are capable of stimulating both the MHC class I and MHC class II presentation pathways in vivo, albeit to differing degrees. Furthermore, depending on the archaeal lipid composition, activation signals to dendritic cells may be provided by archaeosomes.

\section{Materials and methods}

\section{Growth of archaeal strains and lipid preparation}

Table 1 lists the sources of archaea used in this study. Methanogenic cultures of Methanosarcina mazei, Methanococcus jannaschii and M. smithii were grown anaerobically in fermentors on methanol at $35{ }^{\circ} \mathrm{C}$ (Sprott et al. 1994), on $\mathrm{CO}_{2} / \mathrm{H}_{2}$ at $65^{\circ} \mathrm{C}$ (Ferrante et al. 1989), or on $\mathrm{CO}_{2} / \mathrm{H}_{2}$ at $35^{\circ} \mathrm{C}$ (Sprott et al. 1999), respectively. The halophilic cultures were revived from lyophilized samples obtained from the former NRC Culture Collection of halophiles. All cultures, except Haloferax volcanii $^{\mathrm{T}}$ (ATTC 29605), were grown at $35{ }^{\circ} \mathrm{C}$ in HM2 medium (Skerman 1967) modified to increase the $\mathrm{NaCl}$ to $25 \%$ (w/v). Haloferax volcanii was grown in medium ATCC 974 (except agar) at $30{ }^{\circ} \mathrm{C}$. Biomass was generated in a 28-1 New Brunswick Scientific (Edison, NJ) fermentor containing 201 of medium with dissolved oxygen maintained at $20 \%$ saturation.

All cultures were harvested in late stationary phase and stored at $-20{ }^{\circ} \mathrm{C}$ as cell pastes. Fermentation times and biomass yields (wet weight) for the extreme halophiles were $72 \mathrm{~h}$ and $14.6 \mathrm{~g} \mathrm{l}^{-1}$ for Halobacterium halobium; $96 \mathrm{~h}$ and $14.8 \mathrm{~g} \mathrm{l}^{-1}$ for Halococcus morrhuae NRCC strain 16008; $240 \mathrm{~h}$ and $3.2 \mathrm{~g}$ $\mathrm{1}^{-1}$ for $H$. morrhuae NRCC strain 14039; and $72 \mathrm{~h}$ and $5.7 \mathrm{~g} \mathrm{l}^{-1}$ for $H$. volcanii, respectively.

Lipids were extracted from frozen and thawed biomass with methanol:chloroform:water $(2: 1: 0.8, \mathrm{v} / \mathrm{v})$, and the total polar lipid fraction collected by precipitation from cold acetone, as described by Sprott et al. (1995). Polar lipids were dissolved in chloroform, with methanol added if needed, and stored at $4{ }^{\circ} \mathrm{C}$.

\section{Lipid analysis}

Polar lipids obtained from each archaeon were analyzed by fast-atom bombardment mass spectrometry (FAB MS) with a Jeol (Peabody, MA) JMS-AX 505H spectrometer operated at $3 \mathrm{kV}$ in negative ion mode. The xenon gun was operated at $10 \mathrm{kV}$. Current-controlled scans were acquired at a rate of 10 -s full scale. A mixture of triethanolamine and Kryptofix (Sigma) was used as the matrix. Total polar lipids were subjected to thin-layer chromatography on $20 \times 20 \mathrm{~cm}, 0.25 \mathrm{~mm}$ Silica gel 60 glass plates (Merck) and individual spots detected by specific spray reagents. Phospholipids were detected with Zinzade's reagent, aminolipids with ninhydrin, glycolipids with $\alpha$-naphthol, and total lipids with sulfuric acid char reagent (Kates 1986). Sulfate-containing lipids were detected as purple spots (phospholipids appear blue) by immersing a thin-layer chromatograhy plate in $0.016 \%$ Azure A (Sigma) in $1 \mathrm{mM} \mathrm{H}_{2} \mathrm{SO}_{4}$ and destaining with $0.05 \mathrm{M} \mathrm{H}_{2} \mathrm{SO}_{4}$ :methanol (3:1, v/v) (Weerachatyanukul et al. 2001). Methanobrevibacter smithii total polar lipids served as negative controls for sulfate-containing lipids; archaetidyl glycerolsulfate $(\mathrm{m} / \mathrm{z}$ for $[\mathrm{M}-1]$ plus $\left.\mathrm{Na}^{+}=907.8\right)$ and sulfate-triglycosyl archaeol $(\mathrm{m} / \mathrm{z}$ for $[\mathrm{M}-1]=1217.8$ ) served as positive controls.

The lipids sulfate-diglycosyl archaeol, with an $\mathrm{m} / \mathrm{z}=$ 1055.6, and archaetidylglycerol methylphosphate, with an $\mathrm{m} / \mathrm{z}=899.5$, were purified to $99 \%$ purity by thin-layer chro-

Table 1. Sources of archaea and characteristics of their total polar lipid, ovalbumin (OVA)-loaded archaeosomes. Abbreviations of culture collections: $\mathrm{NRC}=$ National Research Council Canada; $\mathrm{NCMB}=$ National Collection of Marine Bacteria; ATCC = American Type Culture Collection; DSM = Deutsche Sammlung von Mikroorganismen und Zellkulturen; and OCM = Oregon Collection of Methanogens. Loading of OVA in archaeosomes used in this study and archaeosome size characteristics are shown.

\begin{tabular}{|c|c|c|c|c|}
\hline Archaeon & Source & Culture collection & Loading ( $\mu$ g OVA mg ${ }^{-1}$ lipid) & Mean diameter $(\mathrm{nm})$ \\
\hline Halobacterium halobium & $\begin{array}{l}\text { Dead Sea, } \\
\text { Delft } 9 \text { strain }\end{array}$ & $\begin{array}{l}\text { NRC } 34020 \\
\text { NCMB } 2152 \\
\text { ATCC } 43214 \\
\text { DSM } 670\end{array}$ & 10 & $94 \pm 44$ \\
\hline Halococcus morrhuae & Dead Sea & NRC 16008 & 32 & $96 \pm 49$ \\
\hline Halococcus morrhuae & Dead Sea & NRC 14039 & 55 & $88 \pm 49$ \\
\hline Methanosarcina mazei S-6 ${ }^{\mathrm{T}}$ & $\begin{array}{l}\text { Sewage sludge plant, } \\
\text { USA }\end{array}$ & $\begin{array}{l}\text { DSM } 2053 \\
\text { ATCC } 43572 \\
\text { OCM } 26\end{array}$ & 26 & $85 \pm 42$ \\
\hline Methanococcus jannaschii JAL-1 & $\begin{array}{l}\text { Submarine hydrothermal } \\
\text { vent, East Pacific Rise }\end{array}$ & $\begin{array}{l}\text { DSM } 2661 \\
\text { OCM } 168\end{array}$ & 44 & $111 \pm 61$ \\
\hline Methanobrevibacter smithii AL1 & Human feces & DSM 2375 & 42 & $190 \pm 116$ \\
\hline
\end{tabular}


matography of total polar lipids from $H$. volcanii. Purity was assessed by FAB MS.

\section{Carbohydrate analysis}

About $1 \mathrm{mg}$ of total polar lipids from various archaea, and $0.2 \mathrm{mg}$ of the purified lipid $(\mathrm{m} / \mathrm{z}=1055)$ from $H$. volcanii and from $H$. morrhuae 14039 were dried and hydrolyzed with $2 \mathrm{M}$ trifluoroacetic acid for $2 \mathrm{~h}$ at $100{ }^{\circ} \mathrm{C}$. D-Ribose was added as an internal standard, and alditol acetate derivatives were prepared for identification and quantification by gas chromatography-mass spectrometry (GC-MS) (Sprott et al. 1999). The total carbohydrate content of each lipid extract was determined by anthrone reaction (Daniels et al. 1994) using D-glucose as the standard, and data reported as percent of total polar lipid extract (w/w).

\section{Archaeosome preparation}

Preparation of ovalbumin (OVA)-loaded archaeosomes was modified from the method described previously (Krishnan et al. 2000a). Briefly, dried total polar lipids (30 mg) were hydrated at $35{ }^{\circ} \mathrm{C}$ in pyrogen-free water containing $5 \mathrm{mg}$ OVA, and the mean diameter of archaeosomes was decreased to about $100 \mathrm{~nm}$ by sonication. Following lyophilization, the sample was rehydrated in a minimal volume of water and incubated overnight at $4{ }^{\circ} \mathrm{C}$. Non-entrapped antigen was removed by centrifugation and washing with water. Loaded archaeosomes were filter sterilized $(0.45 \mu \mathrm{m})$ and assayed for dry mass and protein content (Krishnan et al. 2000a) to determine antigen loading. Finally, archaeosomes were diluted in sterile phosphate-buffered saline (PBS) to achieve $15 \mu \mathrm{g}$ of encapsulated OVA per $0.1 \mathrm{ml}$, and stored at $4{ }^{\circ} \mathrm{C}$ until needed. Mean vesicle diameters were measured with a $5-\mathrm{mW} \mathrm{HeNe}$ laser particle sizer (Nicomp, Santa Barbara, CA).

To prepare archaeosomes for phagocytosis assays, total polar lipids in chloroform were mixed with $0.5 \%$ (w/w) rhodamine B 1,2-dihexadecanoyl-sn-glycero-3-phosphoethanolamine (Molecular Probes, Eugene, OR). Archaeosomes were formed by hydration of dried lipids in water. Their size was reduced by sonication, and they were filter sterilized as described above. Final mean diameters ranged from 85 to $250 \mathrm{~nm}$. Unlabeled liposomes were composed of dimyristoylphosphatidylglycerol (DMPG, Sigma), DMPG containing 20 mol\% $\alpha$-phosphatidylserine (bovine brain, Larodan, Sweden), and L- $\alpha$-phosphatidylinositol (soybean, Sigma).

\section{Immunizations}

Female C57BL/6 mice from Charles River Laboratories (St. Constant, Quebec, Canada), aged 8-10 weeks, were immunized subcutaneously at the base of the tail with $15 \mu \mathrm{g}$ of OVA entrapped by archaeosomes made from the total polar lipids of various archaea. Injections were given at 0 and 3 weeks.

\section{Antigen-specific immune responses}

To evaluate humoral responses, blood was collected in serum separator tubes (Becton Dickinson) from the tail veins of mice, and the sera titrated for anti-OVA antibody (IgG plus IgM) by indirect antigen-specific ELISA, as described previously
(Krishnan et al. 2000a). Cytotoxic T cell responses were assayed by the ${ }^{51} \mathrm{Cr}$-release assay using EL-4 and EG.7 target cells, and antigen-stimulated splenic cells from immunized mice as effectors. For each analysis, splenic cells from duplicate mice were pooled. Details are described elsewhere (Krishnan et al. 2000b) and in the legend to Figure 9.

\section{Activation of bone marrow dendritic cells}

Bone marrow-derived dendritic cells were prepared as described previously (Krishnan et al. 2001), and were consistently $>80 \% \mathrm{CD} 11 \mathrm{c}^{+}$by flow cytometry. Briefly, bone marrow was flushed from the femurs and tibias of C57BL/6 mice, and single cell suspensions were made. Cells were cultured $(1 \times$ $10^{6}$ cells ml $^{-1}$ ) in RPMI 1640 medium (Gibco Invitrogen) supplemented with $8 \%$ fetal bovine serum (FBS) and $5 \mathrm{ng} \mathrm{ml}^{-1}$ of recombinant murine granulocyte macrophage colony stimulating factor (GM-CSF; ID Labs, London, ON, Canada) for $6-8$ days at $37{ }^{\circ} \mathrm{C}$ in $8 \% \mathrm{CO}_{2}$. Non-adherent cells were removed at Days 2 and 4 of culture, and fresh RPMI plus GMCSF and $8 \%$ FBS was added. Dendritic cells were harvested on Days 6-8 as non-adherent cells and $1 \times 10^{5}$ cells $\mathrm{ml}^{-1}$ were incubated in vitro with various concentrations of antigen-free archaeosomes or lipopolysaccharide from Escherichia coli (Sigma), in triplicate in 96-well tissue culture plates, for $72 \mathrm{~h}$ at $37{ }^{\circ} \mathrm{C}, 8 \% \mathrm{CO}_{2}$, in a humidified atmosphere. At $72 \mathrm{~h}$, cell activation was assessed by measurement of dimethylthiazol (MTT) uptake, and supernatants were collected for interleukin-12 (IL-12) assay. Interleukin-12 production was measured by sandwich ELISA (Mosmann and Fong 1989) using mouse IL-12 p40 antibodies (Pharmingen).

\section{Annexin V-FITC labeling}

Exposure of phosphoserine on the outer surface of archaeosomes was detected by calcium-dependent binding of annexin V-FITC (Pharmingen). Unilamellar or multilamellar archaeosomes were incubated for $15 \mathrm{~min}$ in binding buffer and annexin V-FITC at $25^{\circ} \mathrm{C}$. Archaeosomes were washed twice in cold PBS and resuspended in the same buffer containing $1 \%$ formaldehyde and $0.1 \% n$-propylgallate fading inhibitor. Fluorescence was observed microscopically in wet mounts.

\section{Phagocytosis assays}

Peritoneal macrophages were obtained from BALB/c mice 3 days after intraperitoneal injections of $2 \mathrm{ml}$ of sterile $3 \%$ thioglycollate (Oxoid, Nepean, ON, Canada). Macrophages were recovered from euthanized animals by intraperitoneal lavage using 10-ml volumes of RPMI containing $8 \%$ FBS. Cells were treated with red blood cell lysing buffer (Sigma) and macrophages collected by centrifugation. Bone marrow dendritic cells were prepared as described above. Volumes of $1 \mathrm{ml}$ of macrophages or dendritic cells $\left(5 \times 10^{5}\right.$ cells ml $\left.^{-1}\right)$ in RPMI plus $8 \%$ FBS were added to each well of a 24 -well plastic plate and allowed to adhere by incubating for $1 \mathrm{~h}$. Adherent cells were washed twice with $1-\mathrm{ml}$ volumes of cold PBS, and $1 \mathrm{ml}$ RPMI (no serum) was added to each well. Inhibitors were followed immediately by rhodamine-labeled archaeosomes, and cells were incubated in a $\mathrm{CO}_{2}$ incubator at $37^{\circ} \mathrm{C}$ for $15,30,60$ 
and $120 \mathrm{~min}$. Reactions were stopped by removing the incubation medium, washing the cells once in cold PBS, and adding $1 \mathrm{ml}$ of PBS plus $1 \%$ formaldehyde per well. Fluorescent macrophages or dendritic cells were viewed in an Olympus inverted microscope at a magnification of 40 times.

\section{Results}

\section{Screening of archaea}

Total polar lipid extracts of extremely halophilic archaea from the former NRC Collection (Ottawa, Canada) were subjected to negative-ion FAB MS for initial characterization. Included were 7 strains of $H$. morrhuae, 17 strains of $H$. halobium (reclassified as H. salinarum (Ventosa and Oren 1996)), and an unidentified Halococcus species. Three of these aerobic halophiles and three anaerobic methanogens (Table 1) were included in this adjuvant study on the basis of their contrasting polar lipid profiles (Table 2). The total polar lipids of $M$. smithii were included in the adjuvant study as an example of a mixture of archaeols and caldarchaeols (about 3:2) high in phosphoserine head groups (Sprott et al. 1999). Archaeosomes made from these lipids are known to promote $\mathrm{CD}^{+}$(Th1 and $\mathrm{Th} 2$ ) and $\mathrm{CD}^{+}$cytotoxic $\mathrm{T}$ cell activity in mice (Krishnan et al. 2000a, 2000b).

\section{Characterization of archaeosome lipid compositions}

Polar lipid extracts were characterized by FAB MS (Figures 1-3) and polar lipid assignments for $\mathrm{M}^{-}$signals were confirmed by head group analysis, staining reactions following thin-layer chromatography, and descriptions of polar lipid structures from the literature, where available.

The H. halobium polar lipids exhibited $\mathrm{m} / \mathrm{z}$ signals similar to those assigned previously for H. $_{\text {salinarum }}{ }^{\mathrm{T}}$ (Fredrickson et al. 1989, Sprott et al. 1997a); these signals support the structural data reviewed by Kamekura and Kates (1999). This strain of $H$. halobium differs from $H$. salinarum ${ }^{\mathrm{T}}$ by having relatively weak signals for archaetidyl glycerosulfate $(\mathrm{m} / \mathrm{z}=885$ and 885 $\left.+\mathrm{Na}^{+}\right)$and sulfate-tetraglycosyl archaeol $(\mathrm{m} / \mathrm{z}=1379.9)$ (Figure 1). These FAB MS data are otherwise typical of Halobacterium species in general, as illustrated by the presence of a signal at $m / z=1217$ assigned to sulfate-triglycosyl archaeol, and a weak signal at $\mathrm{m} / \mathrm{z}=1055$ typical of sulfate-diglycosyl archaeol.

The FAB MS spectra of the polar lipids from the extremely halophilic $H$. morrhuae strains differed from $H$. halobium by exhibiting major lipid signals at $m / z=1055$ and absent or decreased signals at $m / z=1217$ (Figure 2).

The two strains of $H$. morrhuae could be distinguished from each other on the basis of their lipid structures. First, 14039 contained a higher abundance of sulfate-diglycosyl archaeol, representing $41 \%$ of the archaetidylglycerol methylphosphate signal compared with only $23 \%$ in 16008 (Figure 2). Second, FAB MS analysis of the polar lipids from 14039 revealed a novel signal at $m / z=1291$. A very polar carbohydrate-positive spot of low mobility was separated by thin-layer chromatography of the total polar lipids from 14039, and was not detected in lipid extracts of 16008 (not shown). The FAB MS of the very polar lipid recovered from iodine-stained plates showed an abundance of a lipid at $m / z=1291$. Furthermore, a lipid apparently two hexose units larger than $\mathrm{m} / \mathrm{z}=1291$ was occasionally observed (Figure 2).

Azure A staining was used to distinguish between two possible assignments for signals at $\mathrm{m} / \mathrm{z}=1055$; namely, as sulfate-diglycosyl archaeol, or glucosamine archaetidylinositol reported earlier in Methanosarcina barkeri (Nishihara et al.

Table 2. Percent relative abundance of lipids and lipid components found in the total polar lipids of archaea. Archaetidylserine (A $\left.\mathrm{A}_{\mathrm{S}}-\mathrm{PS}\right)$ contents are from Sprott et al. $(1994,1999)$ and Figure 4. Sugars and inositol were identified and quantified as alditol acetate derivatives by GC MS. The relative contribution of each sugar to the total carbohydrate, measured by anthrone reaction, is shown. Archaetidylglycerol methylphosphate ( $\mathrm{A}_{\mathrm{S}}$-PGP-methyl) and sulfate-glycolipids represent the major lipids of extreme halophiles (+). Of the archaea shown, only M. jannaschii and M. smithii contain caldarchaeols.

\begin{tabular}{|c|c|c|c|c|c|c|}
\hline \multirow[t]{2}{*}{ Lipid component } & \multicolumn{6}{|c|}{ Percent of total polar lipids } \\
\hline & H. halobium & $\begin{array}{l}\text { H. morrhuae } \\
\text { strain } 16008\end{array}$ & $\begin{array}{l}\text { H. morrhuae } \\
\text { strain } 14039\end{array}$ & M. jannaschii & M. mazei & M. smithii \\
\hline $\mathrm{A}_{\mathrm{S}}-\mathrm{PS}$ & 0 & 0 & 0 & 3 & 12.1 & 30 \\
\hline Sulfated-glycolipid & + & + & + & 0 & 0 & 0 \\
\hline $\mathrm{A}_{\mathrm{S}}$-PGP-methyl & + & + & + & 0 & 0 & 0 \\
\hline Total carbohydrate & 5.7 & 6.8 & 9.5 & 9.1 & 0.76 & 7.0 \\
\hline Mannose & 1.86 & 3.54 & 3.75 & 0.032 & 0.0 & 0.14 \\
\hline Glucose & 1.55 & 2.33 & 3.87 & 1.55 & 0.68 & 6.81 \\
\hline Galactose & 2.29 & 0.70 & 1.84 & 0.033 & 0.077 & 0.050 \\
\hline Mannosamine & 0.0 & 0.0 & 0.0 & 0.0 & 0.0 & 0.0 \\
\hline Glucosamine & 0.0 & 0.048 & 0.037 & 7.49 & 0.0 & 0.0 \\
\hline Galactosamine & 0.0 & 0.177 & 0.0 & 0.0 & 0.0 & 0.0 \\
\hline Heptose & 0.0 & 0.0 & 0.0 & 0.0 & 0.0 & 0.0 \\
\hline Inositol & 0.0 & 0.049 & 0.026 & 0.0 & 10.26 & 0.198 \\
\hline
\end{tabular}




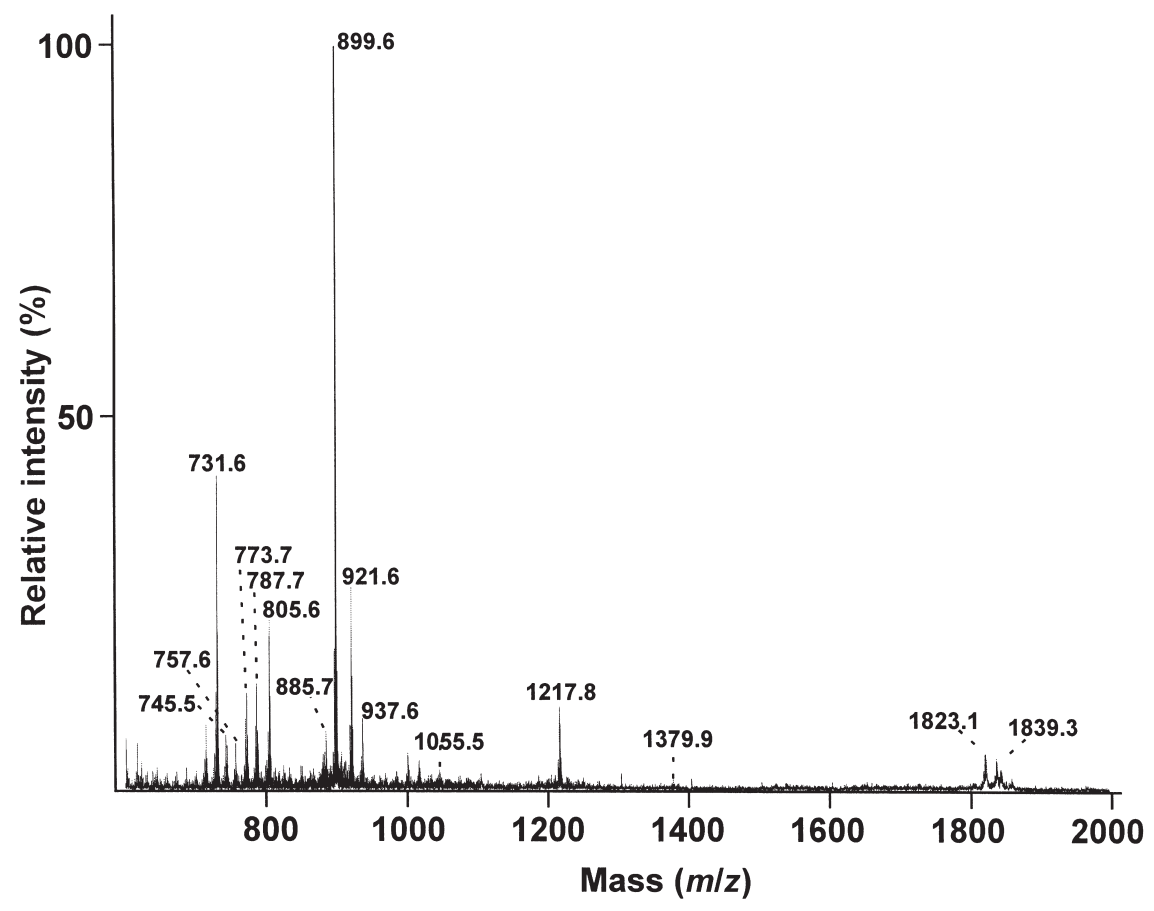

Figure 1. Negative-ion FAB MS spectrum of the total polar lipids from Halobacterium halobium. Assignments correspond to $\mathrm{M}^{-}$signals: $\mathrm{A}_{\mathrm{S}}-\mathrm{P}, \mathrm{m} / \mathrm{z}=$ $731.6 ; \mathrm{m} / \mathrm{z}=745.5,757.6,773.7$ and 787.7 (see text); $\mathrm{A}_{\mathrm{S}}-\mathrm{PG}, \mathrm{m} / \mathrm{z}=805.6$; $\mathrm{A}_{\mathrm{S}}-\mathrm{PG}$-sulfate plus $\mathrm{A}_{\mathrm{S}}-\mathrm{PGP}, \mathrm{m} / \mathrm{z}=$ 885.7; A $_{S}$-PGP-methyl, $m / z=899.6$; A $_{\mathrm{S}}$-PGP-methyl plus $\mathrm{Na}^{+}, \mathrm{m} / z=921.6$; $\mathrm{A}_{\mathrm{S}}$-PGP-methyl plus $\mathrm{K}^{+}, \mathrm{m} / \mathrm{z}=937.6$; sulfate-diglycosyl-A,$m / z=1055.5$; sulfate-triglycosyl-A,$m / z=1217.8$; and sulfate-tetraglycosyl- $\mathrm{A}_{\mathrm{S}}, \mathrm{m} / \mathrm{z}=$ 1379.9. Signals at $\mathrm{m} / z=1823.1$ and 1839.3 are interpreted as $\mathrm{Na}^{+}$and $\mathrm{K}^{+}$ forms of dimers formed from fragment ions during analysis.

1992). Total polar lipids from H. morrhuae 14039 and 16008 and $H$. volcanii, an extreme halophile also characterized by the presence of a major lipid with an $\mathrm{m} / \mathrm{z}$ of 1055 , exhibited purple Azure A positive spots with an $\mathrm{R}_{\mathrm{f}}$ value of 0.27 . As a control to demonstrate the specificity of staining, $M$. smithii polar lipids were separated by thin-layer chromatography and stained with Azure A. No sulfate-positive spots developed, as expected. The lipid spots of $\mathrm{R}_{\mathrm{f}} 0.27$ were also $\alpha$-naphthol-positive and amino- and phosphate-negative. This lipid, when purified from lipid extracts of $H$. volcanii (chosen as a rich source for simple purification) and $H$. morrhuae 14039 , exhibited an $\mathrm{m} / \mathrm{z}$ of 1055.6, and contained only glucose and mannose (1:0.96 and 1:1.16, respectively) in hydrolysates. These data are consistent with the general conclusion that many extreme halophiles (Figure 2) make a sulfate- $\mathrm{Man}_{\mathrm{p}}-\mathrm{Glc}_{\mathrm{p}}$ archaeol (Kamekura and Kates 1999).

Thin-layer chromatography combined with identification of spots with specific spray reagents confirmed the lipid assignments for FAB MS spectra of total polar lipid extracts from extreme halophiles, with the exception that no amino-positive lipids were detected despite the presence of $m / z$ signals indicative of archaetidylethanolamine (expected $\mathrm{m} / \mathrm{z}=774$ ). Indeed, unassigned signals at $\mathrm{m} / \mathrm{z}=745,757,773$ and 787 typically appeared in FAB MS spectra of all extremely halophilic archaeal lipid extracts containing sulfate-glycolipids and archaetidylglycerol methylphosphate. The presence of signals at $m / z=745,757,773$ and 787 in FAB MS spectra of purified sulfate-diglycosyl archaeol and purified archaetidylglycerol methylphosphate (not shown) support their assignment as fragment ions arising from these lipids by phytanyl chain fragmentations.

The polar lipids of M. mazei are composed of archaeol and hydroxy-archaeol analogs of phosphatidylglycerol, phospha- tidylinositol, phosphatidylethanolamine and phosphatidylserine (Nishihara and Koga 1991, Sprott et al. 1994). This lipid extract consists primarily of phospholipids, with only $0.76 \%$ carbohydrate. The sugars were identified as glucose and galactose (9:1), and there was no detectable glucosamine (Table 2), which appears to be inconsistent with the presence of glucosaminyl archaetidylinositol, also at $\mathrm{m} / \mathrm{z}=1055$ and found in the closely related M. barkeri (Nishihara et al. 1992). However, a lipid with an $m / z$ of 1055 was detected by FAB MS in $M$. maze $i$ lipid extracts as a relatively weak signal compared to that from M. barkeri lipids (Sprott et al. 1994), indicating that the concentration of glucosamine may have been below detection limits.

Methanococcus jannaschii is noted for the multiplicity of structures $2 \mathrm{~m} / \mathrm{z}$, units apart arising from synthesis of archaeol and macrocyclic archaeol (Figure 3). Comita et al. (1984) have identified the macrocyclic saturated nature of the latter lipid core by hydrolysis of ether bonds and identification of the released chain as diphytane. Caldarchaeol lipids of higher mass include signals at $m / z=1865$ and 1791 (not shown), typical of caldarchaeols from other methanogen sources. Only a few polar lipid structures have been reported for M. jannaschii (Ferrante et al. 1989). A head group analysis following acid hydrolysis and acetylation revealed the absence of inositol, and a high sugar content consisting of $85 \%$ glucosamine and nearly $15 \%$ glucose (Table 2 ). A dominant polar lipid signal at $\mathrm{m} / \mathrm{z}=934.7$ is consistent with the lipidic glucosamine existing as $\mathrm{N}$-acetylglucosamine archaeol (Figure 3), although part of this lipid signal may arise from a phosphoethanolamine-glucose archaeol lipid of the same $\mathrm{m} / \mathrm{z}$ (Ferrante et al. 1989). From these data, we conclude that the polar lipids of $M$. jannaschii are rich in $\mathrm{N}$-acetylglucosamine archaeol, as well as rich in the lipids with phosphoethanolamine head groups that were 

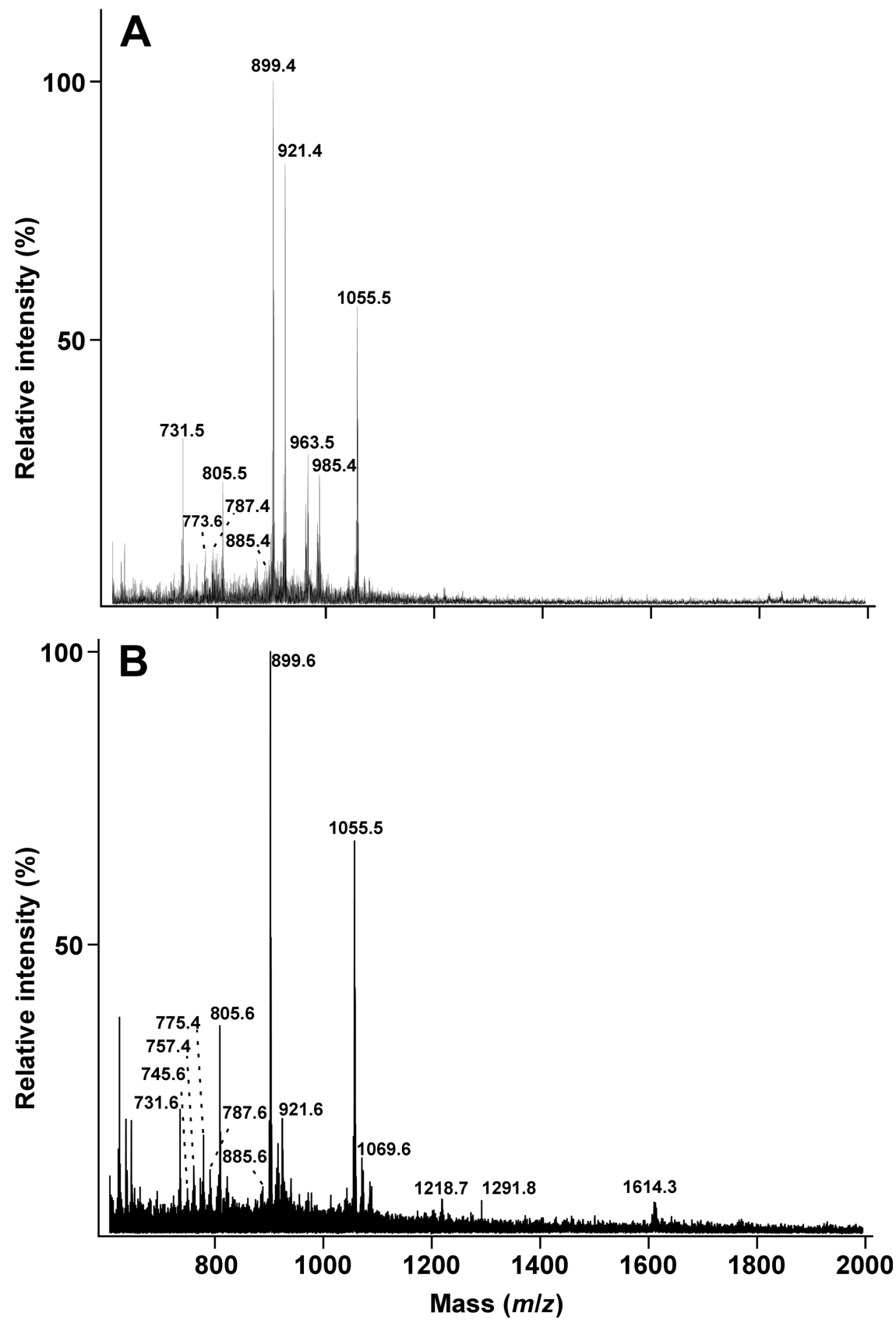

Figure 2. Negative-ion FAB MS spectra of the total polar lipids from Halococcus morrhuae strains 16008 (panel A) and 14039 (panel B). Assignments are reported in the legend to Figure 1, except new signals at $\mathrm{m} / \mathrm{z}=963.5$ and $985.4\left(+\mathrm{Na}^{+}\right)$in panel A, which are interpreted as propionic acid or butyl variations replacing the methyl moiety of PGP-methyl. Note the unidentified signals at $\mathrm{m} / \mathrm{z}=1291.8$ and 1614.3 in panel B.

reported earlier (Ferrante et al. 1989). In addition, phosphoamino lipids of $M$. jannaschii co-migrated on thin-layer chromatography plates with archaetidylserine $(\mathrm{m} / \mathrm{z}=818)$ and diglucosyl caldarchaetidylserine $(\mathrm{m} / \mathrm{z}=1791)$ from $M$. smithii (Sprott et al. 1999) (Figure 4). A phosphoamino lipid less mobile than archaetidylserine was also present in M. jannaschii, as expected for a macrocyclic-archaetidylserine $(\mathrm{m} / \mathrm{z}=816)$. From the relative intensity of ninhydrin staining of total polar lipids separated by thin-layer chromatography, it is estimated that M. jannaschii extracts contained less than $10 \%$ phosphoserine lipids. The absence of inositol (Table 2) excludes the signal at $m / z=891.5$ as a macrocyclic-archaetidylinositol and is tentatively assigned here as a macrocyclic-archaeol with glucose-phosphate moieties.

Polar lipid head group analysis

Carbohydrate accounted for 6 to $11 \%$ of the total polar lipid dry mass in the case of extremely halophilic archaea, and their glycolipids were rich in mannose and sulfate. In contrast, mannose and sulfate were absent or very minor in the methanogen glycolipids. The carbohydrate residues of $M$. smithii lipids were predominantly glucose, as reported previously (Sprott et al. 1999), whereas in the case of M. jannaschii, they were largely $\mathrm{N}$-acetylglucosamine (see also Figure 3 assignments). Although the polar lipids of M. mazei were primarily phospholipids, most (90\%) of the sugar moieties of the minor 


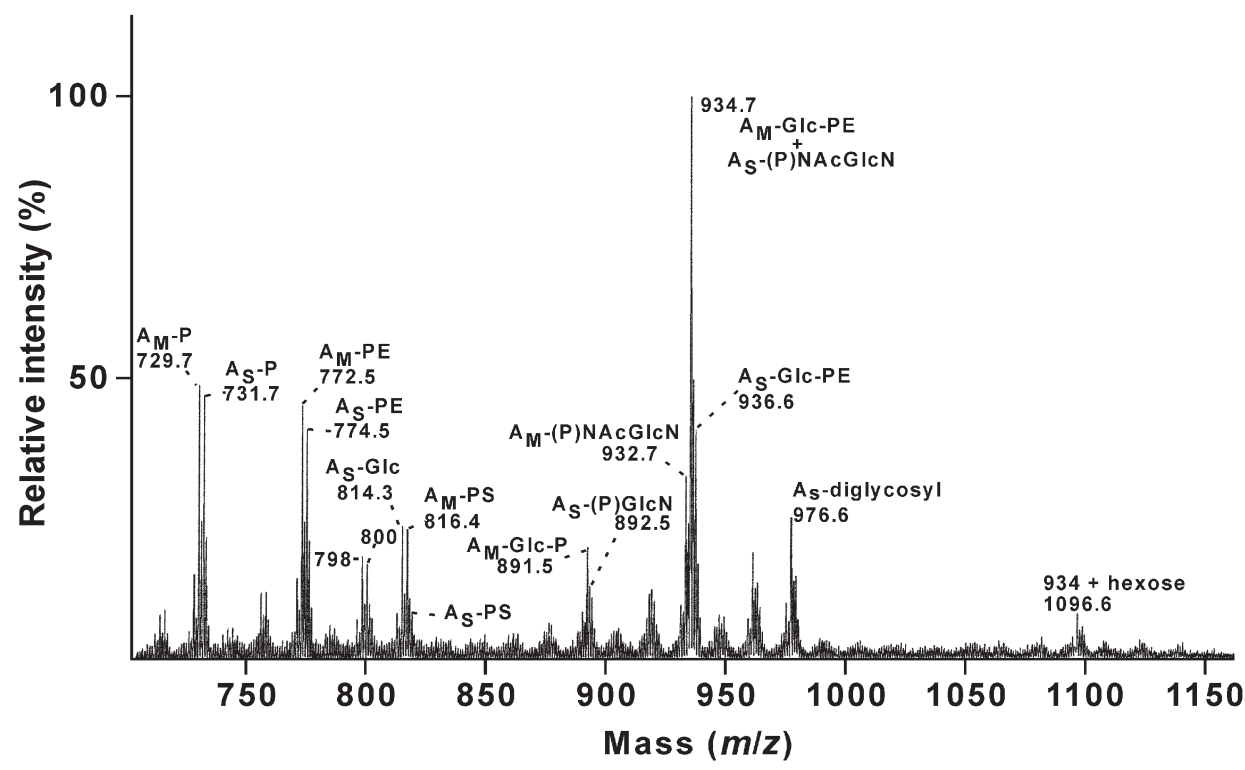

Figure 3. Negative-ion FAB MS spectrum of the total polar lipids of Methanococcus jannaschii. Assignments are shown in the figure and remain tentative for $\mathrm{m} / \mathrm{z}=891.5$, 932.7, 1096.6 and $\mathrm{A}_{\mathrm{S}^{-}}$ (P)NAcGlcN, not reported previously (Ferrante et al. 1989). $(\mathrm{P})=$ position of phosphate unknown. glycolipid component were glucose.

These and other features distinguishing the polar lipids of methanogens from those of extreme halophiles are summarized in Table 2. Archaetidylserine was found in the methanogens and was absent from all extreme halophiles. Also, the archaetidylglycerol methylphosphate lipid represented a major lipid in all extreme halophiles, and was absent in methanogenic archaea. Finally, archaetidylglycerol was a polar lipid typical of extreme halophiles (Figures 1 and 2) and M. mazei, but was not observed among lipids from M. smithii (Sprott et al. 1999) or M. jannaschii (Figure 3).

\section{Orientation of phosphoserine in archaeosomes}

Because phosphoserine head groups in glycerolipids from non-archaeal species have been shown to promote phagocytosis of liposomes through a phosphatidylserine receptor (Fadok et al. 2000), it was important to assess the orientation of archaetidylserine in archaeosomes. Annexin V-FITC labeling was assessed with multilamellar archaeosomes containing various amounts of archaetidylserine and found to bind strongly to archaeosomes prepared from $M$. smithii total polar lipids (Figure 5). Methanococcus jannaschii archaeosomes contained less phosphoserine lipids (Table 2) and bound lower amounts of annexin V. Methanosarcina mazei archaeosomes bound even less label, suggesting an inward orientation of most of the phosphoserine residues. Similar results were observed for the respective 100-nm diameter unilamellar archaeosomes (not shown). Halobacterium halobium archaeosomes contained no phosphoserine and were negative for annexin labeling.

\section{Phagocytosis of archaeosomes}

Thioglycollate-activated murine peritoneal macrophages were used to assess the possibility of receptor-mediated phagocytosis of archaeosomes. Uptake was assessed microscopically to allow an estimate of labeling of the macrophages and to help distinguish surface binding from endocytosis. Initial studies showed that both archaeosome types contrasting in phosphoserine lipid content (H. halobium and $M$. smithii) nearly saturated the uptake systems in these macrophages at about $50 \mu \mathrm{g}$ (dry mass) per ml of RPMI medium per 0.5 million adhered macrophages after a 30-60 min uptake period.

Uptake of 100-nm diameter M. smithii archaeosomes into macrophages of about $15 \mu \mathrm{m}$ diameter was dramatic, resulting in what appeared to be pockets of endocytosed archaeosomes (Figure 6A). Twofold greater amounts of unlabeled archaeosomes composed of M. smithii lipids (Figure 6B) dramatically competed for uptake, in contrast to archaeosomes of $H$. halobium lipids (Figure 6C). $\alpha$-Phosphatidylserine/phosphatidylglycerol (PS/PG) liposomes competed with the uptake system used to endocytose M. smithii archaeosomes (Figure 6D), but phosphatidylinositol (PI) liposomes had less effect even at tenfold concentration (Figure 6E). Phosphatidylglycerol (PG) liposomes also competed, although a 2- to 5fold higher concentration was required compared with $\mathrm{PS} / \mathrm{PG}$ liposomes (not shown).

Because N-ethylmaleimide often inhibits membrane transport, it was tested as an inhibitor of uptake of various archaeosome types by peritoneal macrophages. In addition, the effect of ATP depletion was assessed by using a combination of azide and fluoride to block oxidative and substrate level phosphorylation. For these studies, numerous fields were scored for uptake of fluorescent archaeosomes to ensure that representative fields were photographed. Uptake of both $M$. smithii and $M$. jannaschii archaeosomes was dramatically inhibited by both treatments (Figures 7A and 7B). In contrast, uptake of $M$. mazei archaeosomes, which have relatively less phosphoserine exposed on the outer surface, was inhibited by ATP depletion inhibitors but not by N-ethylmaleimide (Figures 7C and 7E). Halococcus morrhuae 14039 and 16008 and H. halobium archaeosomes with no phosphoserine lipids interacted with the macrophages via a mechanism apparently insensitive to inhi- 


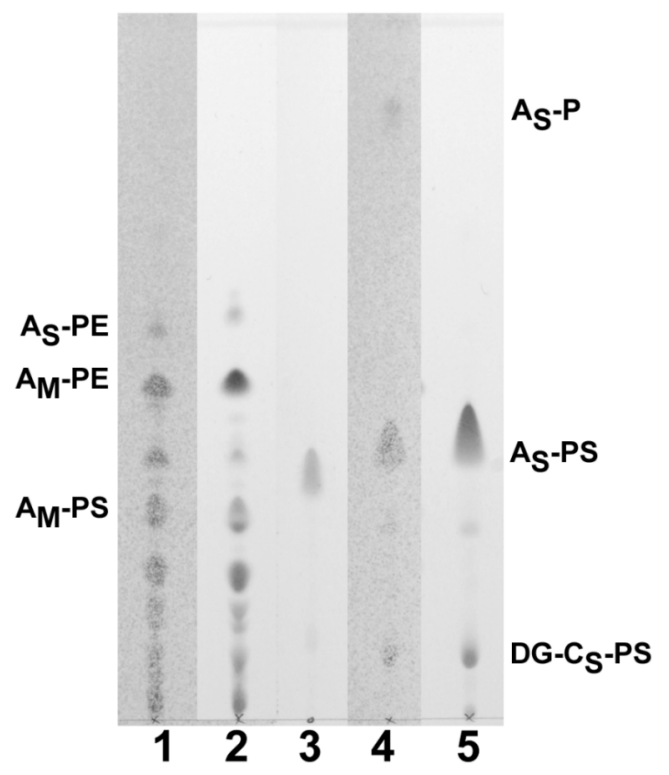

Figure 4. Relative abundance of phosphoserine lipids in total polar lipid extracts of $M$. jannaschii and $M$. smithii shown by thin-layer chromatography. Total polar lipids were separated on silica gel with chloroform:methanol:acetic acid:water (85:22.5:10:4, v/v), and developed with either Zinzade's phosphate stain or ninhydrin amino stain. Total polar lipids of $M$. smithii are shown as a comparative standard known to contain about $30 \mathrm{~mol} \%$ archaetidylserine $\left(\mathrm{A}_{\mathrm{S}}\right.$-PS) and a smaller amount of diglucosyl caldarchaetidylserine (DG-C $\mathrm{C}_{\mathrm{S}}-\mathrm{PS}$ ) (Sprott et al. 1999). Macrocyclic-archaetidylethanolamine ( $\left.\mathrm{A}_{\mathrm{M}}-\mathrm{PE}\right)$ and archaetidylethanolamine $\left(\mathrm{A}_{\mathrm{S}} \mathrm{PE}\right)$ were observed for $M$. jannaschii, as reported previously (Ferrante et al. 1989). Track 1, M. jannaschii, $380 \mu \mathrm{g}$, phosphate stain; Track 2, M. jannaschii, $380 \mu \mathrm{g}$, amino stain; Track 3, PS from bovine brain, phosphate stain; Track 4, M. smithii, $220 \mu \mathrm{g}$, phosphate stain; and Track 5, M. smithii, $330 \mu \mathrm{g}$, amino stain.

bition by either the sulfhydryl inhibitor or by ATP depletion (Figures 7D-7F).

Because dendritic cells are potent antigen presenting cells capable of presenting exogenous antigen to MHC class I by a process known as cross priming (Rodriguez et al. 1999), we tested the effect of these inhibitors on uptake of $M$. smithii archaeosomes in bone marrow-derived dendritic cell cultures. Methanobrevibacter smithii archaeosomes were taken up dramatically by dendritic cells by a mechanism fully inhibited by N-ethylmaleimide and azide plus fluoride. A tenfold decrease in concentration of each inhibitor also caused dramatic inhibitions (not shown).

\section{Adjuvant activity of archaeosomes prepared from total polar lipid extracts}

To evaluate the adjuvant activity of the total polar lipids from the selected archaea, lipid vesicles were prepared with entrapped OVA (OVA-archaeosomes). Ovalbumin loading and size distribution of the vesicles used in these animal trials are shown in Table 1. Loading of the different archaeosome types was similar within a factor of 2 , with the exception of lower OVA loading in the case of $H$. halobium archaeosomes. All size distributions were similar.
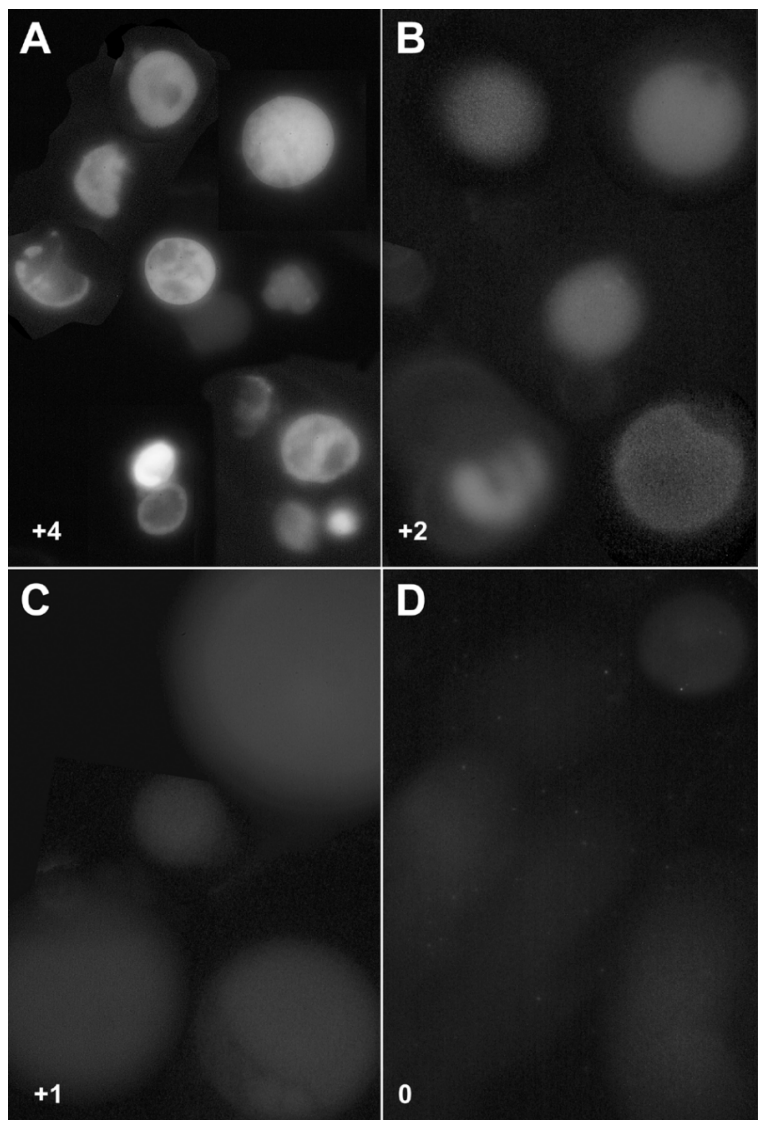

Figure 5. Annexin V-FITC binding to multilamellar archaeosomes composed of the total polar lipids from $M$. smithii (A), M. jannaschii (B), M. mazei (C) and H. halobium (D). Calcium-dependent binding of annexin V-FITC to multilamellar archaeosomes (about $1 \mu \mathrm{m}$ in diameter) was observed in wet mounts. Relative fluorescence is shown in each panel.

Humoral adjuvant activity was measured in the sera of mice 10 days after a single immunization, and again at 49 days post first injections, with a boost given at 3 weeks (Figure 8). AntiOVA antibody titres were low in the case of immunizations with OVA alone. However, equivalent amounts of antigen injected as archaeosome formulations promoted a humoral response that was strongest with $H$. halobium archaeosomes and weakest with archaeosomes composed of $M$. jannaschii total polar lipids. Other archaeosomes were intermediate in humoral adjuvant activities. The greater activity of $\mathrm{H}$. halobium archaeosomes is unlikely to be a property of the relatively higher amounts of lipid injected per dose (Table 1), based on previous data. Loading effects were tested with archaeosomes prepared from the structurally similar lipids of H. salinarum ${ }^{\mathrm{T}}$. Humoral adjuvanting was comparable within the range of 0.35 to $0.72 \mathrm{mg}$ lipids per dose, antigen being constant, and declined only at higher lipid doses (Krishnan et al. $2000 a)$.

Cytotoxic T lymphocyte (CTL) activity in antigen-stimulated splenic cells from mice was also assessed, as this adjuvant activity is initiated by antigen delivery to the cytosol of antigen presenting cells (Figure 9). Killing of EG.7 targets 

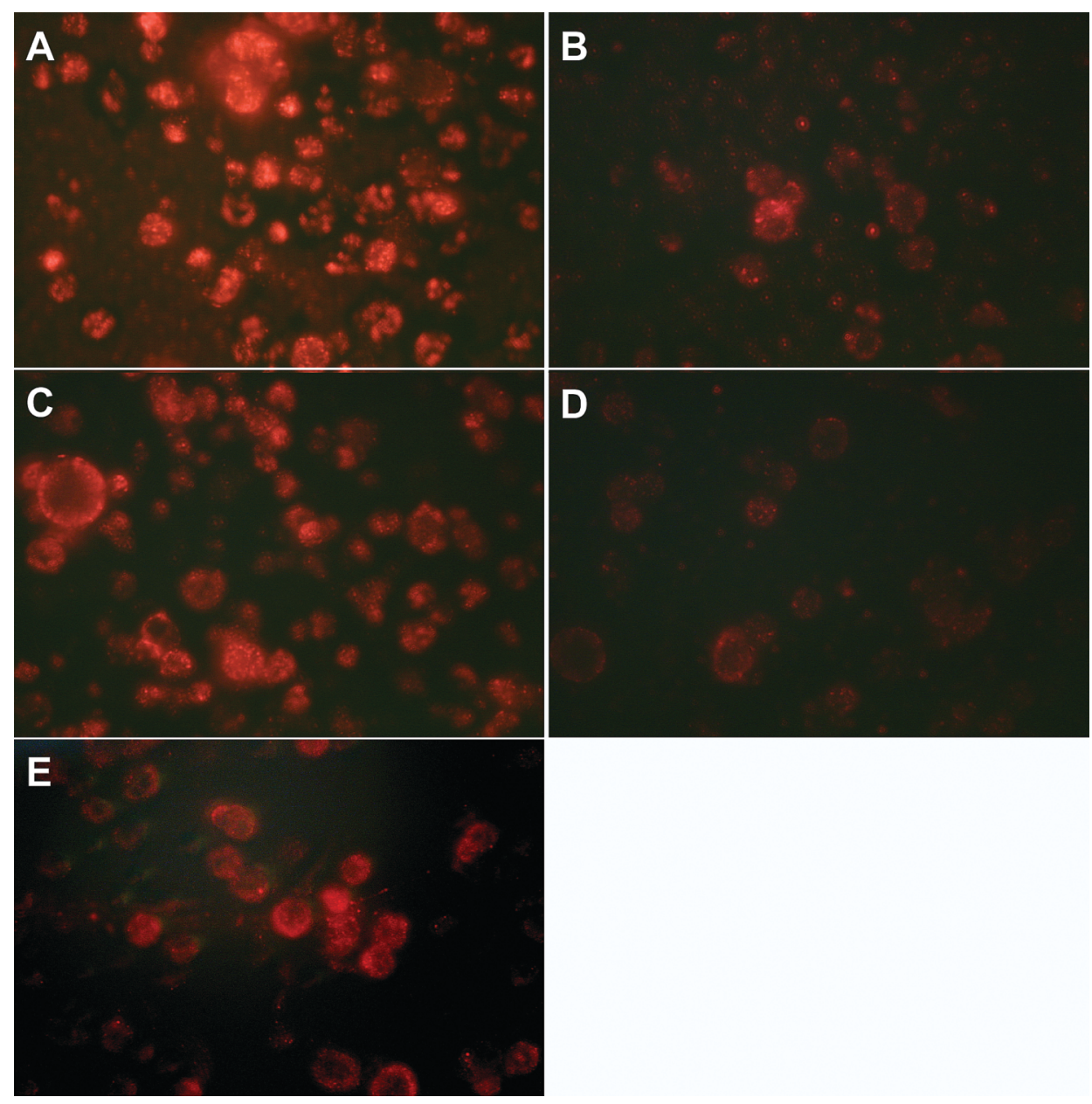

Figure 6. Uptake of rhodamine-labeled $M$. smithii archaeosomes by murine peritoneal macrophages, and competition for uptake by unlabeled archaeosomes or liposomes. Competing unlabeled liposomes or archaeosomes $($ mean diameter $=100 \mathrm{~nm})$ were added immediately prior to addition of rhodaminelabeled M. smithii archaeosomes. Uptake was allowed to occur for 30 min following addition of $25 \mu \mathrm{g}$ of rhodamine-labeled $M$. smithii archaeosomes to $1 \mathrm{ml}$ of RPMI with 0.5 million adhered macrophages. The reaction was stopped by fixing macrophages in $1 \%$ formaldehyde, and photographs were taken using an inverted microscope. (A) no competitor; (B) $50 \mu \mathrm{g}$ unlabeled $M$. smithii archaeosomes; (C) $50 \mu \mathrm{g}$ unlabeled H. halobium archaeosomes; (D) $50 \mu \mathrm{g}$ unlabeled PS/PG liposomes; and (E) $250 \mu \mathrm{g}$ unlabeled PI liposomes. expressing the OVA CTL epitope was dramatic even at 10 days after a single immunization with OVA-archaeosomes from M. smithii, H. halobium and H. morrhuae strain 14039. Other archaeosome compositions produced less killing activity at this early time point. Non-immunized naive mice and mice immunized with OVA (no adjuvant) expressed little to no CTL activity. Non-specific killing of EL-4 targets, which lack expression of the OVA CTL epitope, was not detected with any archaeosome preparation. Twenty-eight days after a second injection, the EG.7 killing potential of CTLs remained high in those mice that received archaeosome injections giving the highest 10-day activity, and killing potential was appropriately absent for the EL-4 targets. Archaeosomes that induced lower initial activity, notably those consisting of lipids of $M$. mazei and $H$. morrhuae strain 16008 , tended to continue to induce a relatively constant CTL activity following a second injection and assay at the later time point, whereas most other archaeosomes induced activity that declined by Day 49 .

\section{Dendritic cell activation}

The possibility that archaeosomes are capable of initiating differing degrees of dendritic cell activation was assessed, as this could provide an explanation for the differences in adjuvant activities of various archaeosome compositions. Antigen-free archaeosomes were prepared from the total polar lipids of H. morrhuae 14039 and 16008, which differed in early CTL adjuvant activities. Lipid vesicles were added to primary cultures of murine bone marrow dendritic cells. Following a 72-h growth period, cultures were assessed by the MTT assay for archaeosome-dependent proliferation or activation, and for secretion of IL-12 as a measure of cell activation. Archaeosomes composed of the polar lipids from 14039 induced striking MTT activities and IL-12 secretions at least comparable on a dry weight basis $\left(10 \mu \mathrm{g} \mathrm{ml}^{-1}\right)$ to the effects of $E$. coli lipopolysaccharide (Figure 10). Microscopic examination indicated that these cultures were activated, and the decreased amounts of IL-12 secreted following the $100 \mu \mathrm{g} \mathrm{ml}^{-1}$ dose is probably a result of overstimulation and induction of apoptosis. In contrast, dendritic cells exposed to archaeosomes composed of lipids from $H$. morrhuae 16008 exhibited relatively little stimulation, as evident by both MTT uptake and IL-12 secretion.

\section{Discussion}

Archaeosome adjuvants are liposome vesicles composed of the polar membrane lipids unique to the Domain Archaea. The ability of archaeosomes to deliver entrapped antigen to both MHC class I and class II pathways for antigen presentation in 


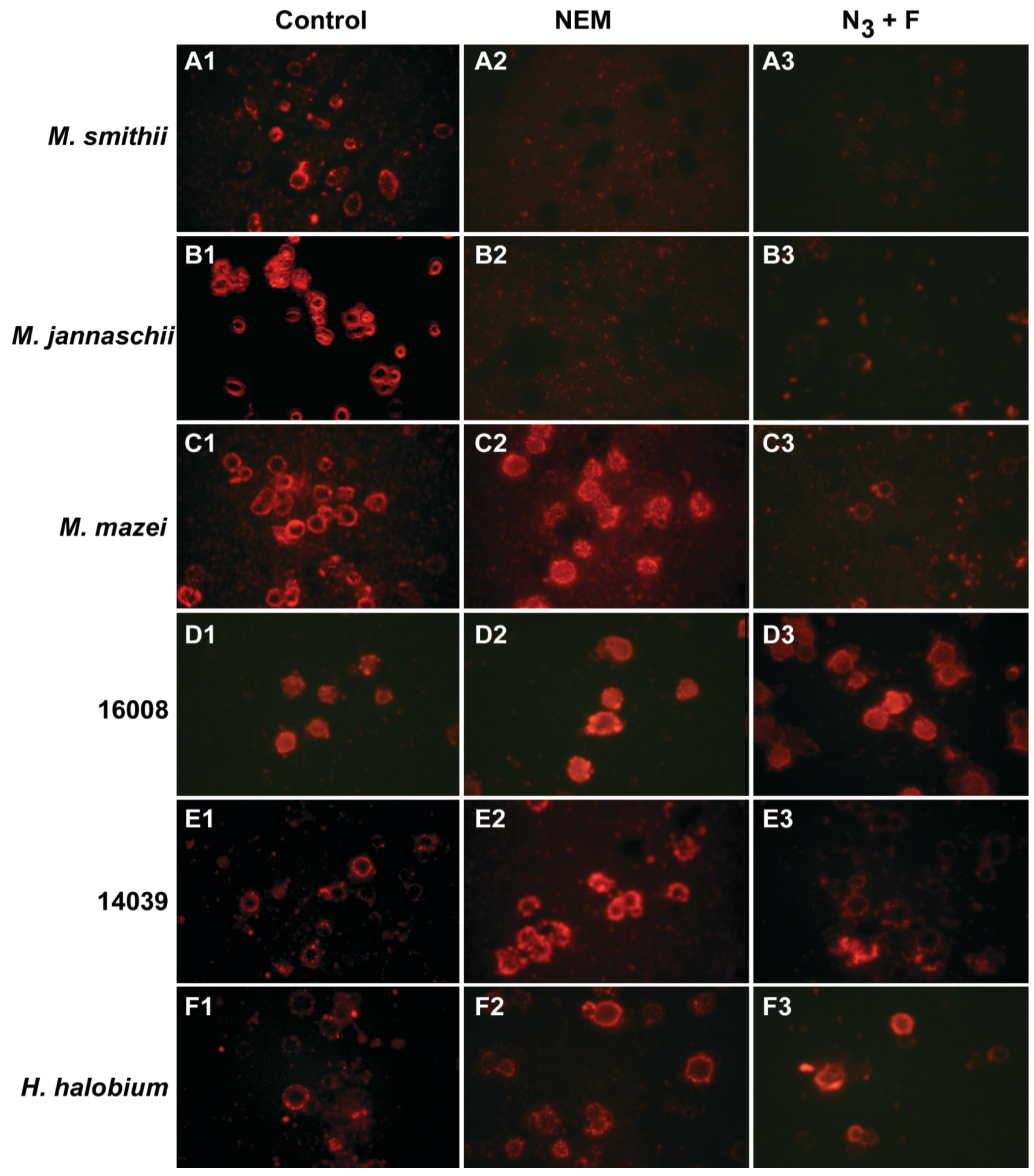

Figure 7. Inhibition of macrophage-mediated uptake of rhodamine-labeled archaeosomes by N-ethylmaleimide and azide plus fluoride. N-ethylmaleimide $(10 \mathrm{mM})$ or $\mathrm{NaN}_{3}$ plus $\mathrm{NaF}(15 \mathrm{mM}$ each) in RPMI were added to adherent thioglycollate-activated peritoneal macrophages for $15 \mathrm{~min}$. Uptake was then initiated by adding $25 \mu \mathrm{g}$ of rhodamine-labeled archaeosomes. Reactions were stopped with $1 \%$ formaldehyde after $60 \mathrm{~min}$, with the exception of panels A and F where uptake was stopped after $15 \mathrm{~min}$. Rhodamine-labeled archaeosomes of total polar lipids of (A) M. smithii, (B) M. jannaschii, (C) M. mazei, (D) H. morrhuae strain 16008, (E) H. morrhuae strain 14039 and (F) H. halobium. Panel 1, no inhibitor; Panel 2, N-ethylmaleimide; and Panel 3, azide plus fluoride.

vivo (Krishnan et al. 2000b) has been extended here to include a number of widely differing and previously untested archae- osome lipid compositions. The model in Figure 11 depicts the ability of archaeosomes to deliver antigen to an antigen pre- 


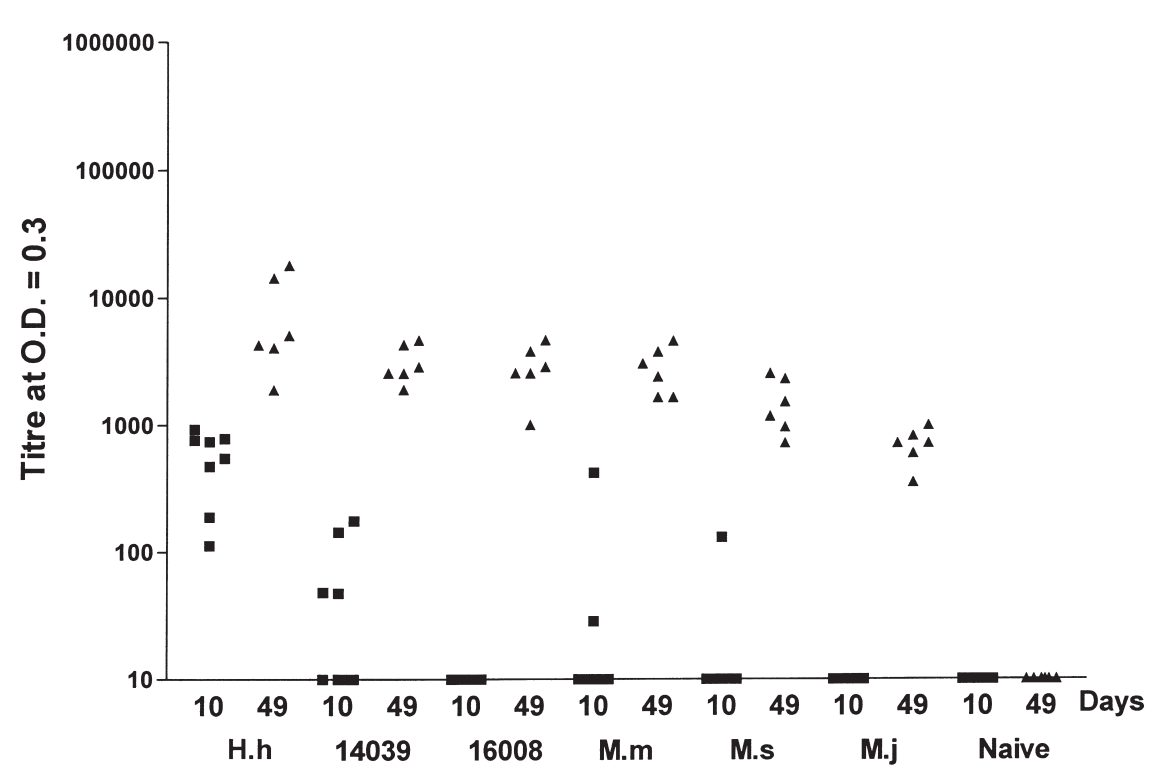

Figure 8. Effect of total polar lipid composition on humoral adjuvant activity of OVA-archaeosomes. C57BL/6 mice were immunized subcutaneously at 0 and 21 days with archaeosomes prepared from the total polar lipids of Halobacterium halobium (H.h); Halococcus morrhuae strain 14039; H. morrhuae strain 16008; Methanosarcina mazei (M.m); Methanobrevibacter smithii (M.s); and Methanococcus jannaschii (M.j). Injections contained $15 \mu \mathrm{g}$ of entrapped OVA. Blood collected after 10 (ם) and 49 days $(\boldsymbol{\Delta})$ was titrated for anti-OVA antibodies by ELISA. Note that 2 mice per group were removed from the study at Day 10 for CTL assays. Titres in sera from mice immunized with $15 \mu \mathrm{g}$ of OVA (no adjuvant) were below the set detection limit. Each data point is for a different mouse. Titres $\leq 10$ are shown as 10 .

\section{A. Day 10}

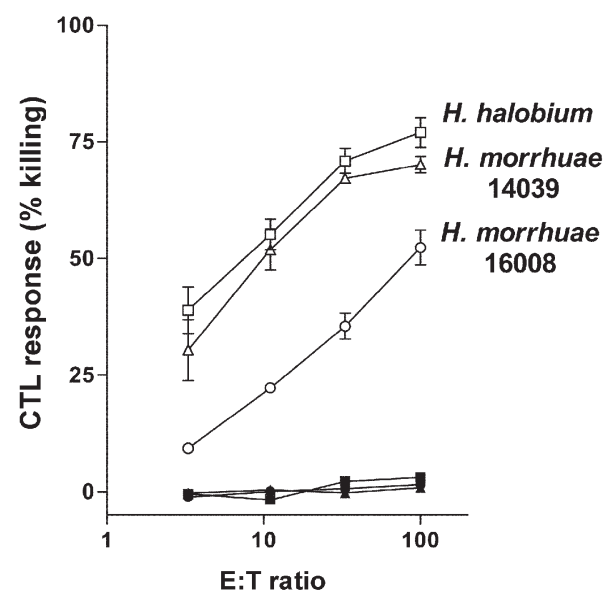

\section{B. Day 49}

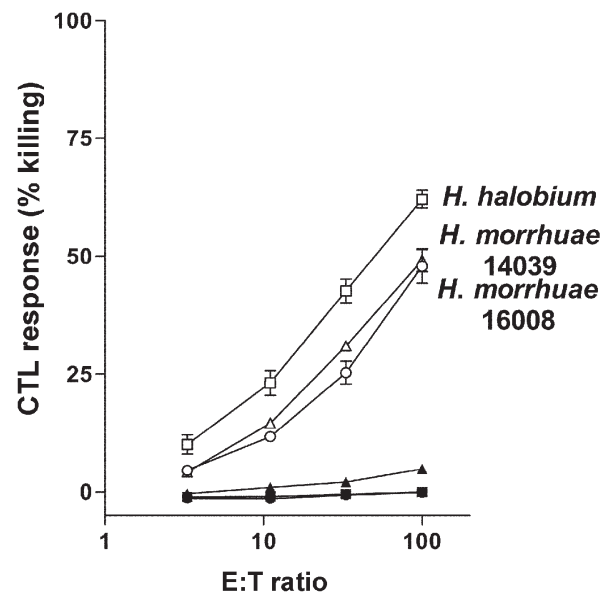

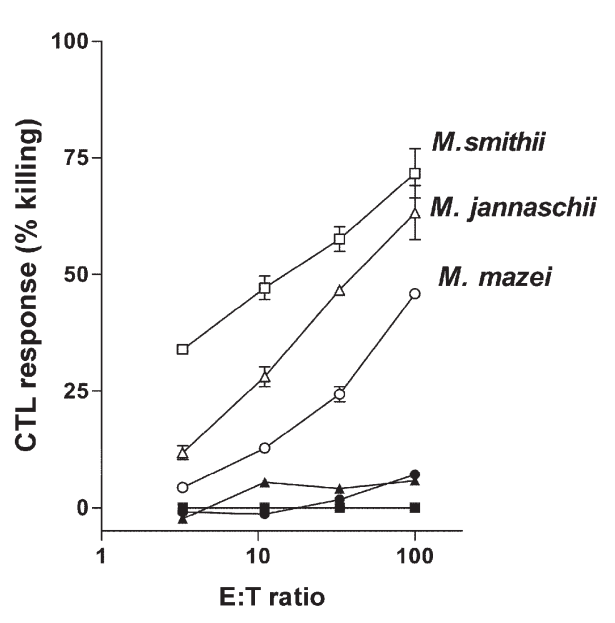

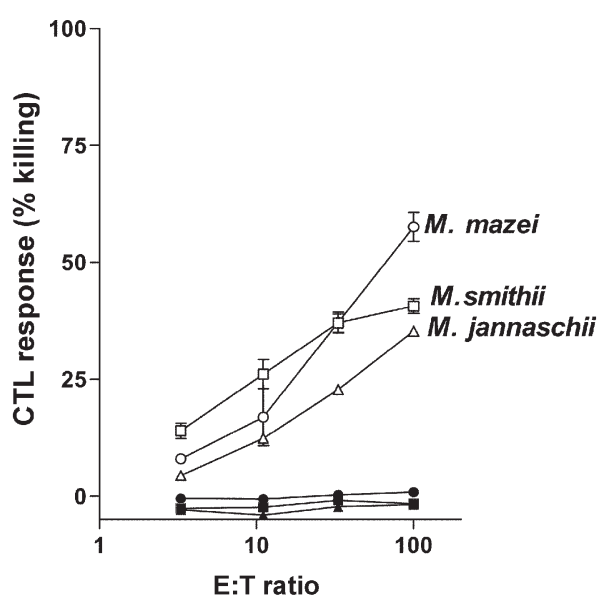

Figure 9. Cytotoxic T-cell response to OVA entrapped in archaeosomes of various lipid compositions 10 days (A) and 49 days (B) post first injection. C57BL/6 mice were immunized subcutaneously on Days 0 and 21 with $15 \mu \mathrm{g}$ OVA entrapped in archaeosomes made from archaeal total polar lipids (Table 1). Mice never immunized (naive) or immunized with OVA (no adjuvant) were included. Spleens were obtained on Days 10 and 49 from duplicate mice in each group and effector cells (E) were prepared by stimulating splenic cells for 5 days with irradiated EG.7 cells. Stimulated effector cells were then combined in various ratios with either ${ }^{51}$ Cr-labeled EL-4 cells (not expressing OVA peptide, and shown as the respective closed symbol) or ${ }^{51} \mathrm{Cr}$-labeled EG.7 targets (expressing OVA peptide; open symbols). After 4-h incubations, killing was assessed in triplicate cultures by the extent of label released from the targets $(\mathrm{T})$; data are shown as \% lysis. Killing of EG.7 targets by splenic cells from OVA (no adjuvant)-immunized mice was 0.64 and $1.81 \%$ for $\mathrm{E}: \mathrm{T}$ ratios of $3: 1$ and $100: 1$, respectively. 

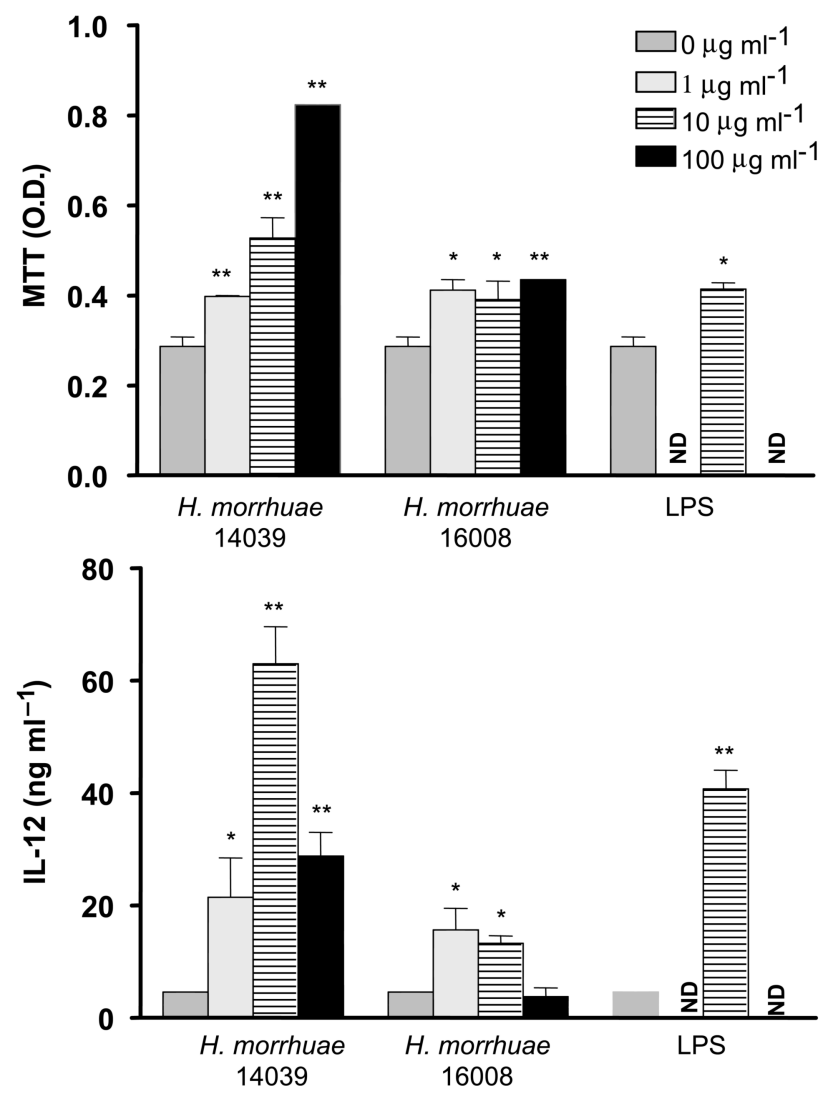

Figure 10. In vitro activation of murine bone marrow dendritic cells by archaeosomes of various lipid compositions. Bone marrow dendritic cells were incubated for $72 \mathrm{~h}$ in the presence of antigen-free archaeosomes prepared from total polar lipids of H. morrhuae strains 14039 and 16008. Means for MTT assays and IL-12 secretions are shown \pm standard deviations for cultures in triplicate. Lipopolysaccharide (LPS) at $10 \mu \mathrm{g} \mathrm{ml}^{-1}$ was used as a positive control. ND = not determined; * and ** = values statistically different by Student's $t$-test at $95 \%$ and $99 \%$ confidence levels, respectively, compared to the R8 medium control.

senting cell for MHC class I and class II presentation as a series of interrelated steps. Using the model, it is possible to rationalize why some archaeosome adjuvants are more effective than others in directing antigen to either MHC presentation pathway. Induction of a humoral response in mice indicates that antigen enters a phagolysosome and is released from the archaeosome vesicle to enter the MHC class II presentation pathway. Although enhanced phagocytosis of archaeosomes (step R1 in Figure 11) compared to other liposome types have been demonstrated in macrophages (Tolson et al. 1996), we provide here the first evidence for receptor-mediated endocytosis of archaeosomes. In thioglycollate-activated peritoneal macrophages, uptake of only M. smithii, M. mazei and M. jannaschii archaeosomes, all of which exhibited annexin $\mathrm{V}$ surface labeling, was inhibited by ATP depletion using treatment with azide plus fluoride. Along with more potent competition for uptake by PS liposomes compared to liposomes composed of PI or PG, these data indicate PS receptor-mediated endocytosis, as reported recently for PS-containing liposomes

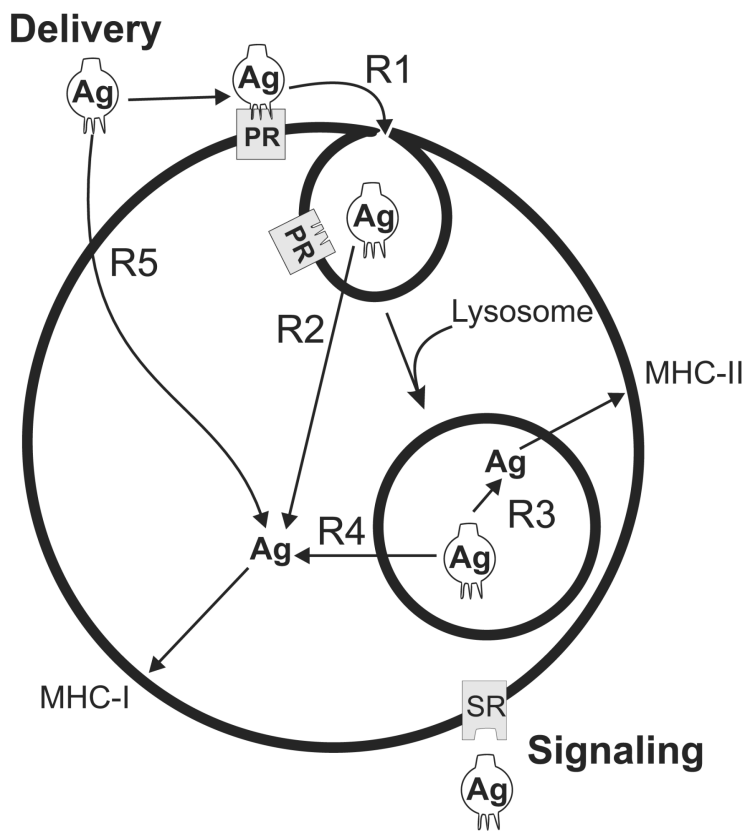

Figure 11. Hypothetical model for delivery of antigen (Ag) encapsulated in archaeosomes to MHC class I (MHC-I) and MHC class II (MHC-II) pathways of antigen presenting cells. A phagocytosis receptor (PR) is shown interacting with an archaeosome vesicle to promote endocytosis (R1). Fusion with lysosomes is shown to be followed by release of $\mathrm{Ag}$ (R3) for processing and presentation of peptides by MHC-II. Ag delivery to the cytosol for MHC-I presentation may occur in theory by direct fusion of archaeosomes with the plasma membrane (R5), or fusion with the endosome (R2) or phagolysosome (R4) membranes. Cell signaling receptors may be activated by archaeosomes either before or after endocytosis.

(Fadok et al. 2000). Caldarchaeol bipolar lipids typical of M. smithii lipids, and caldarchaeol plus macrocyclic archaeol lipids characteristic of M. jannaschii lipids, impart stability to the vesicles (Mathai et al. 2001) and may be anticipated to decrease the rate of step R3. Although the rate of step R3 has yet to be measured in situ, these archaeosomes did result in relatively low antibody responses in comparison to other archaeosome types (Figure 8). Nevertheless, even the antibody response generated by M. smithii archaeosomes is generally superior to that obtained with $\mathrm{PC} / \mathrm{PG} /$ cholesterol liposomes and alum (Krishnan et al. 2000a).

Delivery of antigen to the MHC class I pathway requires that archaeosomes release part of their antigen load to the cytosol, either directly by fusion with the plasma membrane of antigen presenting cells (step R5), or with the membrane of the phagosome following endocytosis (steps R2 and R4). No information is currently available to define how well archaeal lipids might fuse with antigen presenting cell membranes. However, properties common to all archaeal lipid cores may explain, in part, the capacity of all archaeosome compositions to deliver encapsulated antigen for MHC class I presentation. Without considering head group effects, these properties are the regularly branched isopranoid chains composed of 20, 25, or 40 carbons, linked via ether bonds to a glycerol backbone with stereochemistry in mirror image to the glycerolipids of 
Bacteria or Eucarya.

Phagocytosis of archaeosomes may be influenced by expression of various receptors on phagocytic cells, including the mannose receptor, the endocytic receptor CD36, the phosphatidylserine receptor, and scavenger-receptors recognizing phospholipids (Rigotti et al. 1995). A structural analysis of lipidic head groups, coupled with the demonstrated expression on phagocytic cells of various receptors (Somersan and Bhardwaj 2001), suggested that various archaeosome types may interact differently with cell surfaces. This was clearly the case in our study. Methanobrevibacter smithii, M. mazei and M. jannaschii lipid extracts contained archaetidylserine and formed archaeosomes that labeled more or less intensely with annexin V. All archaeosome types, including those composed of lipids from extreme halophiles that lack archaetidylserine, were observed microsopically to be bound (tethered) to the surface of the phagocyte through receptors or other interactions not fully understood. However, only the archaeosomes of M. smithii, M. mazei and M. jannaschii, all of which exhibited annexin labeling, were endocytosed via an ATP-requiring system. These results are in accordance with the conclusions of Hoffmann et al. (2001) that apoptotic cells "tethered" to phagocytes by various receptors require the ligation or "tickling" of the phosphatidylserine receptor by phosphatidylserine to promote membrane vesicle formation and "bystander" uptake by macropinocytosis.

However, archaeosomes lacking phosphoserine head groups also served as adjuvants in vivo for both antibody and CTL responses. These archaeosome types were adsorbed by thioglycollate-activated peritoneal macrophages by an Nethylmaleimide-insensitive mechanism. We suggest that the in vivo presentation of antigen by these archaeosome types occurs by "tethering" with various receptors, with the "tickling" signal to the PS receptor provided by apoptotic cells expressing PS. Archaeosomes high in surface-exposed PS head group would be "tethered" and would be capable of providing the "tickling" signal. Indeed, efficient cross presentation of exogenous antigen occurs through $M$. smithii adjuvants, resulting in MHC class I presentation of encapsulated protein in IC 21 macrophages (Krishnan et al. 2000b).

We surmise that two events contribute to the potent adjuvant action of archaeosomes: first, antigen delivery to the appropriate antigen processing compartment, and second, immunostimulation. A requirement to associate the antigen with the archaeosome to promote the full humoral response (Sprott et al. 1997b, Krishnan et al. 2000a) is consistent with an antigendelivery function for archaeosomes. We have also shown that M. smithii archaeosomes are potent recruiters and activators of dendritic cells (Krishnan et al. 2001). Halococcus morrhuae 14039 and 16008 differentially induced CTL responses despite considerable similarity in their lipid structures (Figures 2 and 9). However, as differences in the in vivo adjuvant activity are evident only at early time points (Figure 9), it is possible that both archaeosomes possess equal abilities to deliver antigen but differ in cell activation. Indeed, only archaeosomes from 14039 promoted IL-12 secretion in dendritic cell cultures (Figure 10) and contained the novel, very polar lipid with an $\mathrm{m} / \mathrm{z}$ value of 1291 that stained as a sulfoglycolipid. Further studies are required to evaluate this lipid for immunoactivating properties.

There are growing numbers of examples where bacterial components serve as agonists to activate toll-like receptors of antigen presenting cells as danger signals to activate the innate immune system (Lien and Ingalls 2002). It is possible that Toll-like receptors are involved in archaeosome-mediated immunostimulation as well. Why archaeal lipids, as surface components of a domain of non-pathogenic bacteria, should serve as danger signals remains a subject of speculation, but may reflect their capacity to be recognized as foreign, or to mimic surface components of pathogens. Glycosyl phosphatidylinositol (GPI) anchors from a protozoan parasite are known to activate Toll-like receptor- 2 at concentrations in the $\mu \mathrm{M}$ to low $\mathrm{nM}$ range, depending on structural details of GPI (Campos et al. 2001). Activation of this receptor by archaeal analogs of GPI, already reported in the polar lipid extracts from $M$. barkeri (Nishihara et al. 1992), may, for those archaeosomes containing this lipid, serve as another clue to explain their strong adjuvant activity.

\section{Acknowledgments}

We acknowledge Ken Chan for performing FAB MS analyses, Lise Deschatelets for contributions to biomass generation and lipid extraction, and Tom Devecseri for photography. This is Publication No. 4466 of the National Research Council Canada.

\section{References}

Campos, M.A.S., I.C. Almeida, O. Takeuchi, S. Akira, E.P. Valente, D.O. Procopio, L.R. Travassos, J.A. Smith, D.T. Golenbock and R.T. Gazzinelli. 2001. Activation of Toll-like receptor-2 by glycosylphosphatidylinositol anchors from a protozoan parasite. J. Immunol. 167:416-423.

Comita, P.B., R.B. Gagosian, H. Pang and C.E. Costello. 1984. Structural elucidation of a unique macrocyclic membrane lipid from a new, extremely thermophilic, deep-sea hydrothermal vent archaebacterium, Methanococcus jannaschii. J. Biol. Chem. 259: $15,234-15,241$.

Conlan, J.W., L. Krishnan, G.E. Willick, G.B. Patel and G.D. Sprott. 2001. Immunization of mice with lipopeptide antigens encapsulated in novel liposomes prepared from the polar lipids of various Archaeobacteria elicits rapid and prolonged specific protective immunity against infection with the facultative intracellular pathogen, Listeria monocytogenes. Vaccine 19:3509-3517.

Daniels, L., R.S. Hanson and J.A. Phillips. 1994. Chemical analysis. In Methods for General and Molecular Bacteriology. Eds. P. Gerhardt, R.G.E. Murray and N.R. Krieg. American Society for Microbiology, Washington, D.C., 518 p.

Fadok, V.A., D.L. Bratton, D.M. Rose, A. Pearson, R.A.B. Ezekewitz and P.M. Henson. 2000. CD36 is required for phagocytosis of apoptotic cells by human macrophages that use either a phosphatidylserine receptor or the vitronectin receptor $\left(\alpha_{v} \beta_{3}\right)$. Nature 405 $85-90$.

Ferrante, G., J.C. Richards and G.D. Sprott. 1989. Structures of polar lipids from the thermophilic, deep-sea archaeobacterium Methanococcus jannaschii. Biochem. Cell Biol. 68:274-283. 
Fredrickson, H.L., J.W. de Leeuw, A.C. Tas, J. van der Greef, G.F. LaVos and J.J. Boon. 1989. Fast atom bombardment (Tandem) mass spectrometric analysis of intact polar ether lipids extractable from the extremely halophilic archaebacterium Halobacterium cutirubrum. Biomed. Environ. Mass Spectrom. 18:96-105.

Hoffmann, P.R., A.M. deCathelineau, C.A. Ogden, Y. Leverrier, D.L. Bratton, D.L. Daleke, A.J. Ridley, V.A. Fadok and P.M. Henson. 2001. Phoshatidylserine (PS) induces PS receptor-mediated macropinocytosis and promotes clearance of apoptotic cells. J. Cell Biol. 155:649-659.

Kamekura, M. and M. Kates. 1999. Structural diversity of membrane lipids in members of Halobacteriaceae. Biosci. Biotechnol. Biochem. 63:969-972.

Kates, M. 1986. Techniques of lipidology: isolation, analysis, and identification of lipids. 2nd Edn. Elsevier, NY, pp 220-225 and 240-242.

Kates, M. 1988. Structure, physical properties, and function of archaebacterial lipids. In Biological Membranes: Aberrations in Membrane Structure and Function. Eds. M.L. Karnovsky, A.M. Leaf and L.C. Bolis. Liss, New York, pp 357-384.

Kates, M. 1992. Archaebacterial lipids: structure, biosynthesis and function. Biochem. Soc. Symp. 58:51-72.

Krishnan, L., C.J. Dicaire, G.B. Patel and G.D. Sprott. 2000a. Archaeosome vaccine adjuvants induce strong humoral, cell-mediated, and memory responses: Comparison to conventional liposomes and alum. Infect. Immun. 68:54-63.

Krishnan, L., S. Sad, G.B. Patel and G.D. Sprott. 2000b. Archaeosomes induce long-term $\mathrm{CD}^{+}$cytotoxic $\mathrm{T}$ cell response to entrapped soluble protein by the exogenous cytosolic pathway, in the absence of CD4 ${ }^{+} \mathrm{T}$ cell help. J. Immunol. 165:5177-5185.

Krishnan, L., S. Sad, G.B. Patel and G.D. Sprott. 2001. The potent adjuvant activity of archaeosomes correlates to the recruitment and activation of macrophages and dendritic cells in vivo. J. Immunol. 166:1885-1893.

Lien, E. and R.R. Ingalls. 2002. Toll-like receptors. Crit. Care Med. 30:1-11.

Mathai, J.C., G.D. Sprott and M.L. Zeidel. 2001. Molecular mechanisms of water and solute transport across archaebacterial lipid membranes. J. Biol. Chem. 276:27,266-27,271.

Mosmann, T.R. and T.A. Fong. 1989. Specific assays for cytokine production by T cells. J. Immunol. Methods 116:151-158.

Nishihara, M. and Y. Koga. 1991. Hydroxyarchaetidylserine and hydroxyarchaetidyl-myo-inositol in Methanosarcina barkeri: polar lipids with a new core portion. Biochim. Biophys. Acta 1082: 211-217.

Nishihara, M., H. Morii and Y. Koga. 1987. Structure determination of a quartet of novel tetraether lipids from Methanobacterium thermoautotrophicum. J. Biochem. 101:1007-1015.
Nishihara, M., M. Utagawa, H. Akutsu and Y. Koga. 1992. Archaea contain a novel diether phosphoglycolipid with a polar head group identical to the conserved core of eucaryal glycosyl phosphatidylinositol. J. Biol. Chem. 267:12,432-12,435.

Rigotti, A., S.L. Acton and M. Krieger. 1995. The class B scavenger receptors SR-B1 and CD36 are receptors for anionic phospholipids. J. Biol. Chem. 270:16,221-16,224.

Rodriguez, A., A. Regnault, M. Kleijmeer, P. Ricciardi-Castagnoli and S. Amigorena. 1999. Selective transport of internalized antigens to the cytosol for MHC class I presentation in dendritic cells. Nature Cell Biol. 1:362-368.

Skerman, V.B.D. 1967. A guide to the identification of the genera of bacteria. 2nd Edn. Williams and Wilkins, Baltimore, MD, $261 \mathrm{p}$.

Somersan, S. and N. Bhardwaj. 2001. Tethering and tickling: a new role for the phosphatidylserine receptor. J. Cell Biol. 155:501-504.

Sprott, G.D., C.J. Dicaire and G.B. Patel. 1994. The ether lipids of Methanosarcina mazei and other Methanosarcina species, compared by fast atom bombardment mass spectrometry. Can. J. Microbiol. 40:837-843.

Sprott, G.D., C.G. Choquet and G.B. Patel. 1995. Purification of ether lipids and liposome formation from polar lipid extracts of methanogenic archaea. In Archaea. A Laboratory Manual. Eds. F.T. Robb, A.R. Place, K.R. Sowers, H.J. Schreier, S. DasSarma and E.M. Fleischmann. Cold Spring Harbor Laboratory, Cold Spring Harbor, NY, pp 329-340.

Sprott, G.D., B.J. Agnew and G.B. Patel. 1997a. Structural features of ether lipids in the archaeobacterial thermophiles Pyrococcus furiosis, Methanopyrus kandleri, Methanothermus fervidus, and Sulfolobus acidocaldarius. Can. J. Microbiol. 43:467-476.

Sprott, G.D., D.L. Tolson and G.B. Patel. 1997b. Archaeosomes as novel antigen delivery systems. FEMS Microbiol. Lett. 154: $17-22$.

Sprott, G.D., J.-R. Brisson, C.J. Dicaire, A.K. Pelletier, L.A. Deschatelets, L. Krishnan and G.B. Patel. 1999. A structural comparison of the total polar lipids from the human archaea Methanobrevibacter smithii and Methanosphaera stadtmanae and its relevance to the adjuvant properties of their liposomes. Biochim. Biophys. Acta 1440:275-288.

Tolson, D.L., R.K. Latta, G.B. Patel and G.D. Sprott. 1996. Uptake of archaeobacterial liposomes and conventional liposomes by phagocytic cells. J. Liposome Res. 6:755-776.

Ventosa, A. and A. Oren. 1996. Halobacterium salinarum nom. corrig., a name to replace Halobacterium salinarum (ElazariVolcani) and to include Halobacterium halobium and Halobacterium cutirubrum. Int. J. Syst. Bacteriol. 46:347.

Weerachatyanukul, W., M. Rattanachaiyanont, E. Carmona, A. Furimsky, A. Mai, A. Shoushtarian, S. Sirichotiyakul, H. Ballakier, A. Leader and N. Tanphaichitr. 2001. Sulfogalactosylglycerolipid is involved in human gamete interaction. Mol. Reprod. Dev. 60: $569-578$. 

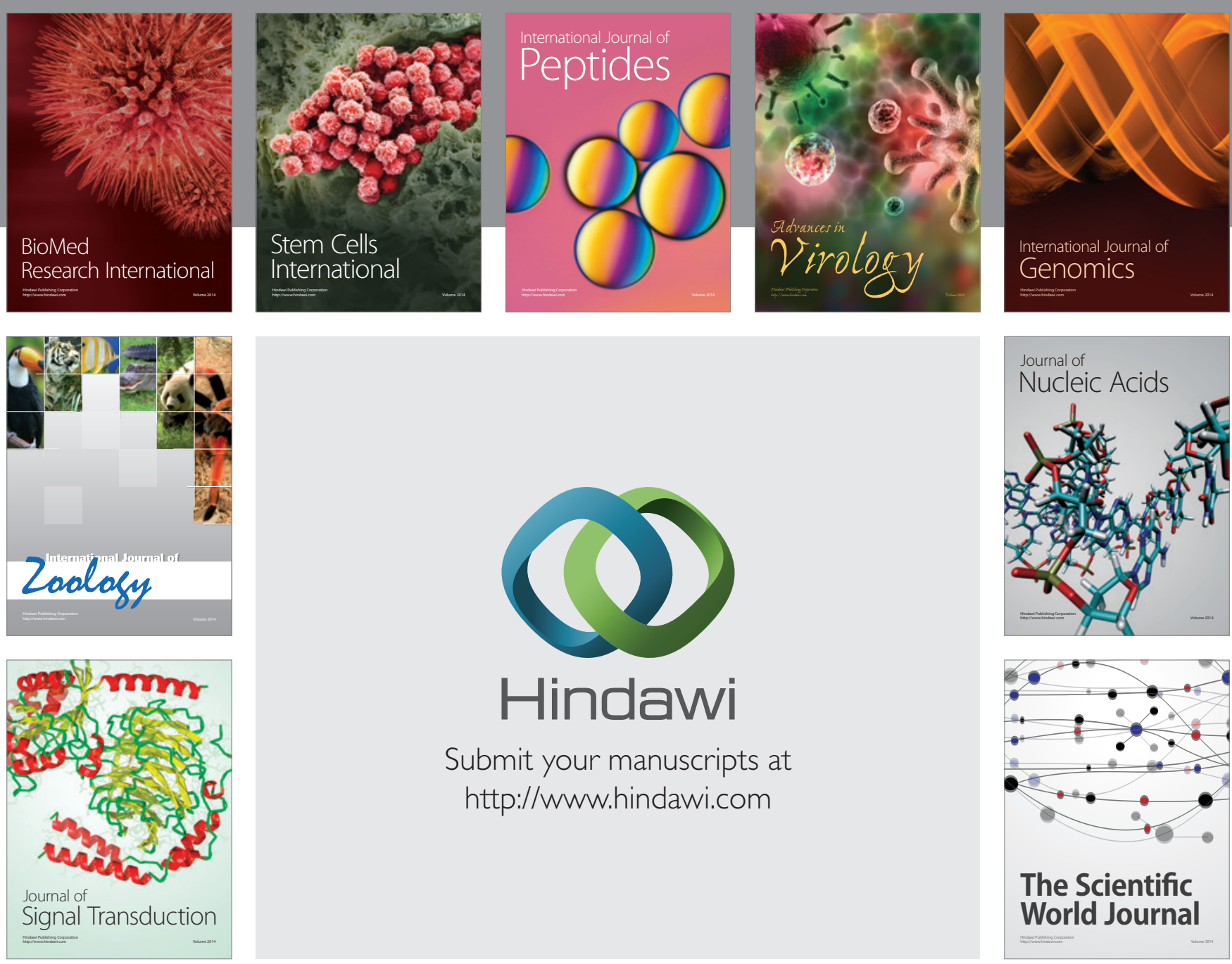

Submit your manuscripts at

http://www.hindawi.com
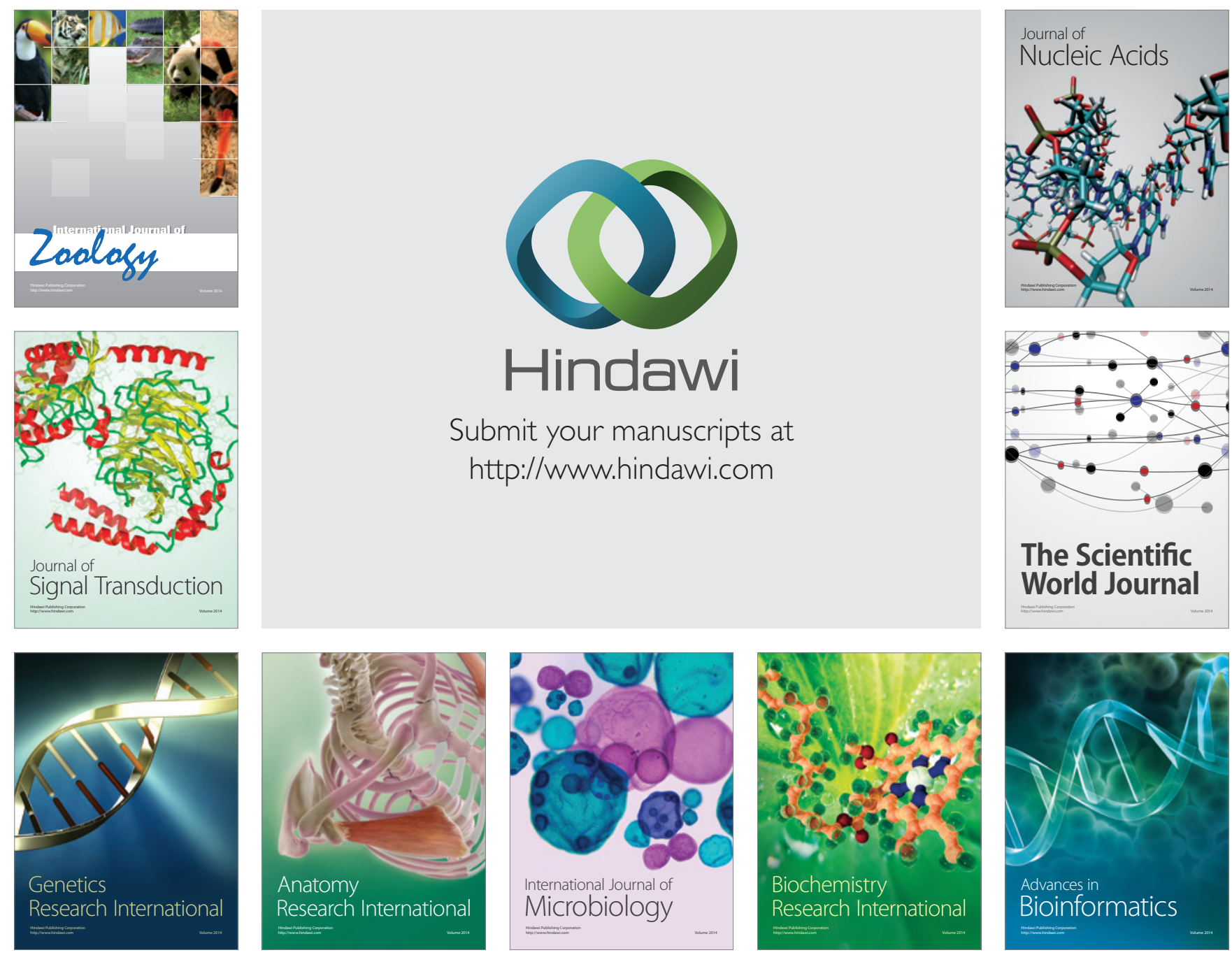

The Scientific World Journal
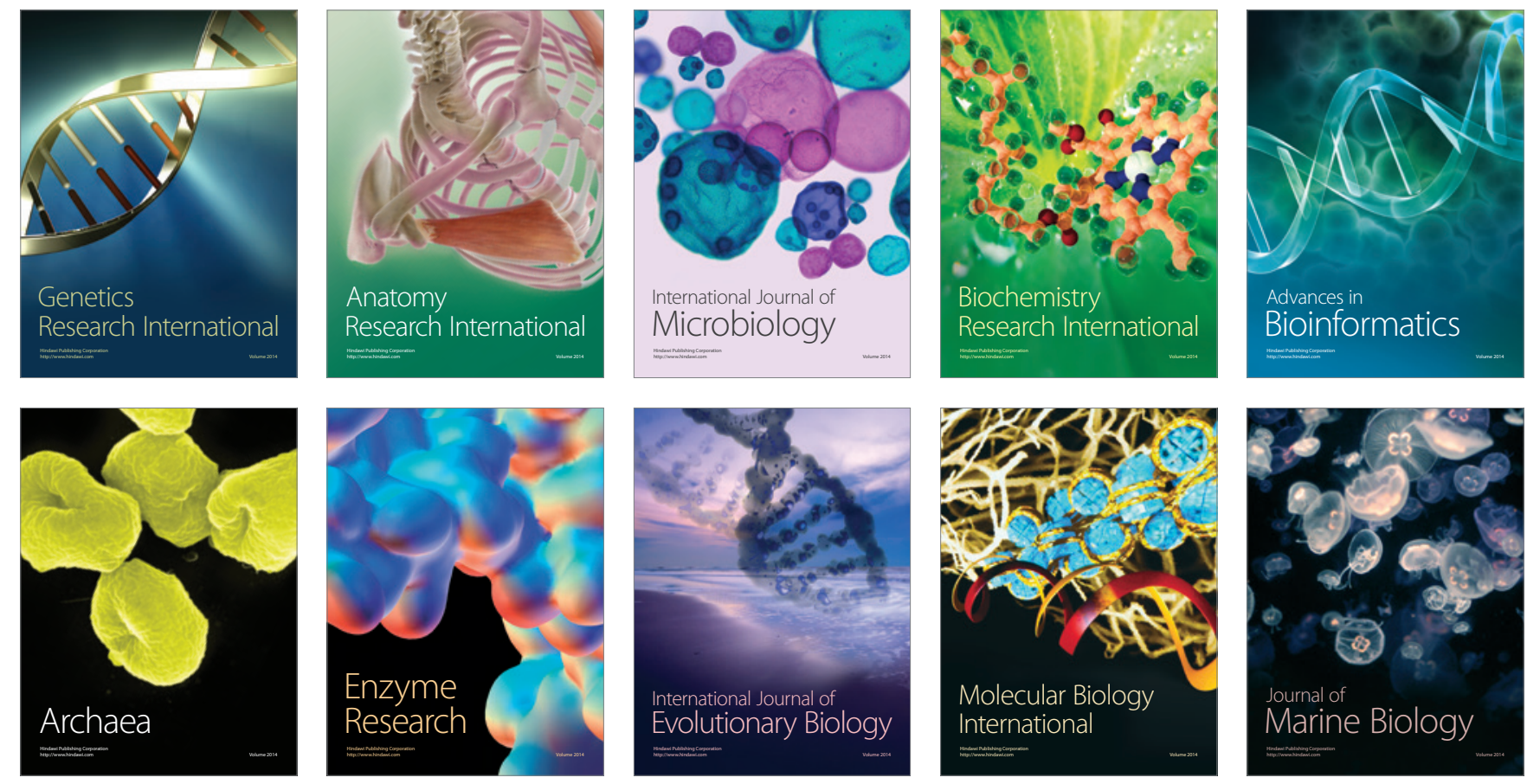